\title{
FOTOELETROCATÁLISE EM SEMICONDUTORES: DOS PRINCÍPIOS BÁSICOS ATÉ SUA CONFORMAÇÃO À NANOESCALA
}

\author{
Alexandre L. B. Baccaro e Ivano G. R. Gutz* \\ Departamento de Química Fundamental, Instituto de Química, Universidade de São Paulo, 05508-000 São Paulo - SP, Brasil
}

Recebido em 09/08/2017; aceito em 08/11/2017; publicado na web em 13/12/2017

\begin{abstract}
PHOTOELECTROCATALYSIS ON SEMICONDUCTORS: FROM THE FUNDAMENTALS TO ITS CONFORMATION AT THE NANOSCALE LEVEL. The science of semiconductors, essential in electronics, is pivotal also for the most active research fields of environmental science and engineering today - the development of solar energy conversions and advanced oxidation processes, exemplified by the harvesting of sun daylight to produce electric energy, environmentally friendly fuels and to clean up water from harmful pollutants. The advancement of such fields relies on the fundamentals of the photocatalysis at semiconductors, summarized in this review in language familiar to chemists. The theory and experimental onrush emerged mainly during the first half of the $20^{\text {th }}$ century but the rising interest in the science of nanostructured materials in recent decades, besides many insights about the potential of this scale-down of sizes, also forced a revision of the theoretical models. Essentially, the interfacial model of the space-charge layer cannot explain the behavior of nanoparticulate films, even at doped conditions comparable to monocrystalline materials. The present work encompasses the conformation of classical photocatalytic models to the nanoscale size, critically reviewing their features and role for modern electrochemical applications.
\end{abstract}

Keywords: photoelectrocatalysis; monocrystalline semiconductors; nanoparticulate semiconductors; space-charge layer; band bending.

\section{INTRODUÇÃO}

O tema fotocatálise já foi alvo de diversas revisões na literatura, inclusive em alguns manuscritos de cunho exaustivo com centenas de referências. Nesse sentido, destacam-se entre os trabalhos clássicos o do professor Michael R. Hoffmann e col. ${ }^{1}$ que acumula mais de 17 mil citações desde 1995 e os do professor Akira Fujishima e col., ${ }^{2,3}$ sobre o $\mathrm{TiO}_{2}$, com cerca de 7 mil e 4 mil citações desde os anos de 2000 e 2008, respectivamente. No Brasil, em língua portuguesa, sobressaem-se os trabalhos de revisão do professor Wilson Jardim e col. ${ }^{4,5}$ visando a discussão da aplicação do $\mathrm{TiO}_{2}$ para remediação ambiental e a discussão de mecanismos de fotodegradação de compostos orgânicos catalisados por ele. A fotoeletrocatálise, entretanto, nunca foi focalizada em trabalhos de revisão em vernáculo. Por algumas vezes, ela foi abordada em trabalhos de inovação técnica contemplando novas aplicações, ${ }^{6-9}$ mas não uma visão fundamentada e sistematizada do tema balizada em literatura selecionada e acompanhada de discussão crítica do estado da arte e possíveis tendências. A fundamentação teórica da fotoeletrocatálise remonta ao final da Segunda Guerra Mundial, com os estudos da semicondução no silício e germânio orientados por Lark-Horovitz ${ }^{10}$ e que desencadearam o enorme avanço tecnológico representado por componentes eletrônicos como diodos e transistores, formados por junções entre semicondutores com dopagem diferente, presentes hoje em praticamente todos os dispositivos eletrônicos. Os componentes semicondutores também se impuseram na detecção e emissão de radiação eletromagnética, servindo de exemplos os fotodiodos e os diodos emissores de luz (LEDs). Assim, segue a fundamentação teórica da matéria.

\section{A TEORIA DE BANDA}

Por definição simples, um semicondutor é um material com condutividade elétrica mensurável que, ao contrário dos condutores metálicos, aumenta com a temperatura. Para compreender melhor os

*e-mail: gutz@iq.usp.br seus mecanismos de condução, é importante conhecer um pouco de suas características físicas e, principalmente, alguns dos princípios da teoria do orbital molecular.

Os sólidos podem ser considerados a união de um número virtualmente infinito de átomos, de modo que o seu posicionamento sucessivo em linha leva à superposição dos orbitais adjacentes para a formação de ligações. Através da combinação linear de dois orbitais atômicos é originado um orbital molecular ligante e um orbital molecular antiligante (dois orbitais moleculares). À medida que mais átomos são enfileirados, mais orbitais moleculares são formados pela interferência das funções de onda de seus orbitais atômicos, levando à formação de um conjunto de orbitais não-degenerados com baixa diferença de energia entre níveis consecutivos. Sugere-se de modo aproximado a formação de um contínuo de níveis de energia entre o orbital ligante de menor energia e o orbital antiligante de maior energia, a chamada banda (Figura 1). Quanto maior a força de interação entre os átomos vizinhos, maior é a diferença de energia entre esses níveis e, portanto, mais larga é a banda. $\mathrm{O}$ aumento do número de átomos enfileirados e orbitais moleculares formados eleva o número de níveis internos da banda e a chamada densidade de estados (número de níveis contidos em uma fração de largura infinitesimal da banda), reduzindo a diferença de energia entre níveis consecutivos e tornando o modelo ainda mais próximo do real. ${ }^{11}$

Cada banda pode ser classificada de acordo com o tipo de orbital atômico que a constitui. A Figura 1 representa a formação de uma "banda s", sendo possível a formação de "banda p" ou ainda "banda d" pela combinação dos respectivos orbitais atômicos quando disponíveis. Como os orbitais "d" são mais energéticos do que os "p" que, por sua vez, são mais altos que os "s" em uma mesma camada de valência, há frequentemente a formação de uma falha entre as bandas formadas, uma região vazia entre níveis ou orbitais moleculares, chamada de banda proibida. A diferença de energia delimitada pela sua largura é chamada de Band Gap (Eg). A existência da banda proibida (Band Gap) está condicionada à largura das bandas consecutivas e à separação energética dos tipos de orbitais envolvidos na formação de cada uma. Forças interatômicas elevadas 


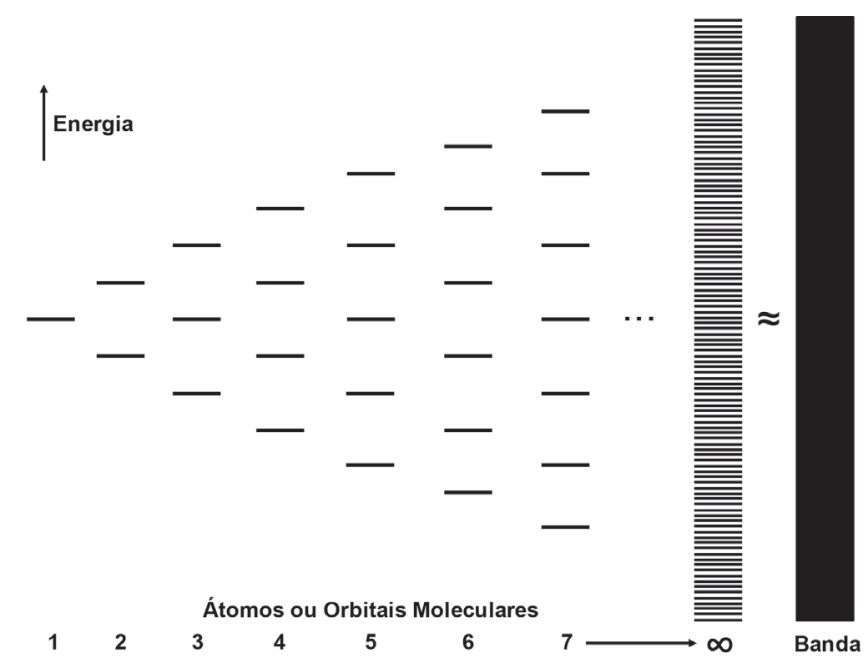

Figura 1. Representação esquemática puramente pictorial do enfileiramento crescente de átomos com a combinação linear de seus orbitais atômicos do tipo s para a formação de orbitais moleculares $\sigma_{s} e \sigma_{s}$. Quando o número de átomos enfileirados tende ao infinito, observa-se a formação de um quasi-contínuo de níveis que é aproximado a um contínuo, constituindo-se o modelo de banda. Exemplo de banda s. Baseado em figura da obra de Shriver e Atkins ${ }^{l}$

e energias de orbitais atômicos similares geralmente induzem a sobreposição de bandas.

A ocupação dos orbitais em bandas é ditada pela distribuição de Fermi-Dirac, um algoritmo estatístico sigmoidal semelhante à distribuição de Boltzmann, mas com a restrição de ocupação de apenas dois elétrons por nível. ${ }^{12}$

$$
f(E)=\frac{1}{1+e^{(E-\mu) / k T}}
$$

em que $f(E)$ representa a probabilidade de um estado com energia "E" estar ocupado após o equilíbrio termodinâmico ser alcançado, $\mathrm{T}$ é a temperatura absoluta do sistema em Kelvin, $\mathrm{k}$ é a constante de Boltzmann e $\mu$ representa o potencial químico total dos elétrons. Em especial, a energia equivalente ao potencial químico do sistema $(\mathrm{E}=\mu)$ merece atenção: neste valor, a probabilidade atinge $50 \%$ $(0,5 / 1,0)$ de chance de ocupação. Esse nível é chamado de nível de Fermi $\left(E_{f}\right)$. O nível de Fermi não corresponde necessariamente a um nível real, podendo se localizar no meio da banda proibida (falha) onde não há orbitais. É um parâmetro de suma importância na caracterização de materiais, pois, juntamente com a estrutura, possibilita prever seu comportamento elétrico. A banda localizada imediatamente acima do nível de Fermi é chamada de Banda de Condução (BC ou Banda Vazia), e por se constituir de orbitais de maior energia, apresenta níveis de baixa probabilidade de ocupação. A banda localizada imediatamente abaixo do nível de Fermi é chamada de Banda de Valência (BV ou Banda Cheia) e, por constituir-se de orbitais de menor energia, encontra maior probabilidade de ocupação. Em sólidos, os elétrons apenas podem atuar como transportadores de carga quando há estados eletrônicos vacantes na banda, uma circunstância plausível somente quando há promoção de parte dos elétrons da banda de valência para a banda de condução.

Em metais, como as bandas são largas e os níveis mais altos da BV são energeticamente comparáveis aos mais baixos da BC, observa-se a sobreposição de bandas com o $\mathrm{E}_{\mathrm{f}}$ localizado nessa região (Figura 2). Os elétrons da $\mathrm{BV}$ conseguem atingir a $\mathrm{BC}$ como estados termicamente acessíveis, de modo que à temperatura ambiente $(298,15 \mathrm{~K})$, a BC encontra-se parcialmente ocupada e a BV não completamente preenchida. Assim, pela ação de um campo elétrico, é possível transportar carga. Em isolantes, $\mathrm{E}_{\mathrm{f}}$ encontra-se dentro de um Band Gap largo (Figura 2), muito distante das bordas de qualquer uma das bandas e de qualquer estado com capacidade de transporte de carga. Os elétrons permanecem isolados na banda de valência cheia, não apresentando estados que permitam mobilidade frente a um campo elétrico. Em semicondutores, a distância da BC para a BV é pequena (Figura $2-$ Band Gap $<4 \mathrm{eV}$ ), sendo que o nível de Fermi se encontra aproximadamente no centro do Band Gap $\left(\mathrm{E}_{\mathrm{f}}=1 / 2 \mathrm{Eg}\right)$. Desse modo, alguns níveis inferiores da Banda de Condução são termicamente acessíveis para elétrons no topo da Banda de Valência à temperatura ambiente $(\approx 298,15 \mathrm{~K})$ que, após a excitação, transformam-se em transportadores de carga $\left(\mathrm{e}_{\mathrm{BC}}^{-}\right)$, assim como os estados vacantes deixados na BV, chamados de lacunas $\left(\mathrm{h}^{+}{ }_{\mathrm{BV}}\right)$, que conferem maior grau de liberdade ao restante de elétrons ali contidos. Esses níveis de transportadores de carga formados puramente por excitação térmica são conhecidos como níveis intrínsecos.

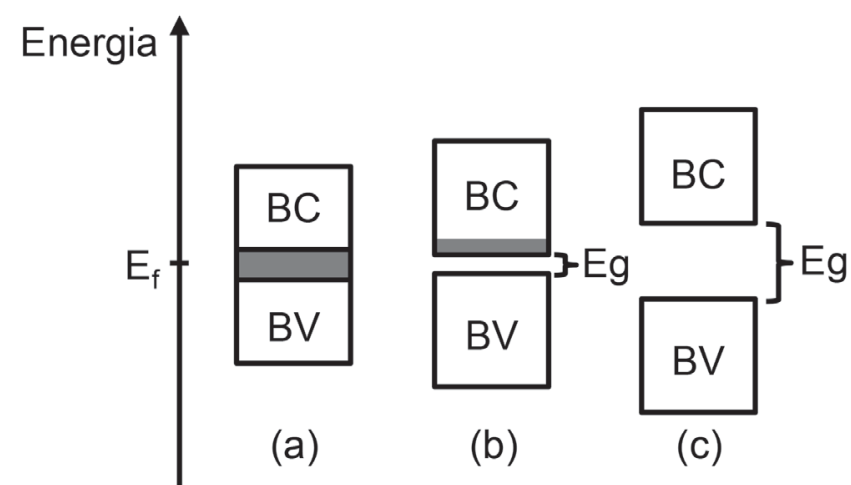

Figura 2. Representação esquemática de diagramas de bandas típicos para (a) condutores eletrônicos (p. ex. metais), (b) semicondutores e (c) isolantes. $E_{g}$ : Band Gap; BV: banda de valência; BC: banda de condução; $E_{f}$ : nível de Fermi a 298,15 K; Sombreamento cinza aponta a presença de estados ocupados com capacidade de transporte de carga

A formação de transportadores de carga $\left(\mathrm{e}^{-}{ }_{\mathrm{BC}} / \mathrm{h}^{+}{ }_{\mathrm{BV}}\right)$ em semicondutores lhes confere condutividade superior a de um isolante nas mesmas condições. Entretanto, a condutividade de ambos os materiais apresenta uma dependência com a temperatura do tipo de Arrhenius, ${ }^{13}$ à qual se aplica o valor de gap de energia entre o fundo da banda de condução $\left(\mathrm{E}_{\mathrm{BC}}\right)$ e o nível de Fermi $\left(\mathrm{E}_{\mathrm{f}}\right)$ em analogia à Energia de Ativação $\left(\mathrm{E}_{\mathrm{a}}=\mathrm{E}_{\mathrm{BC}}-\mathrm{E}_{\mathrm{f}} \approx \mathrm{Eg} / 2\right)$ :

$$
\sigma=\sigma_{0} e^{\frac{-E g}{2 k T}}
$$

em que $\sigma$ é a condutividade em $\mathrm{S} \mathrm{cm}, \sigma_{0}$ é um fator pré-exponencial, Eg é a energia de separação entre a borda das bandas (Band Gap), $\mathrm{k}$ é a constante de Boltzmann e T é a temperatura absoluta em Kelvin. Qualitativamente, é possível concluir que o gap de energia entre o fundo da $\mathrm{BC}$ e o nível de Fermi $\left(\mathrm{E}_{\mathrm{BC}}-\mathrm{E}_{\mathrm{f}}\right)$ é um parâmetro determinante da condutividade de um semicondutor intrínseco ou isolante, qualquer que seja a temperatura de estudo. Inclusive, esse pode ser o principal parâmetro de diferenciação, uma vez que isolantes até podem ser considerados semicondutores em temperaturas elevadas e, em zero Kelvin, todo semicondutor será um isolante.

Um novo rearranjo da Eq. 2, apresentado abaixo na Eq. 3, explicita a relação de decaimento exponencial do produto das concentrações dos transportadores intrínsecos (lacunas e elétrons) com a energia de Band Gap (Eg), atenuado pela energia térmica do sistema (kT) e de acordo com um fator pré-exponencial correspondente à densidade efetiva de estados nas bordas das bandas de condução e valência, $\mathrm{N}_{\mathrm{c}}$ e $\mathrm{N}_{\mathrm{v}}$ respectivamente: ${ }^{14}$ 


$$
[n][p]=N_{c} N_{v} e^{\frac{-E g}{k T}}
$$

Os valores de densidade de estados $\mathrm{N}_{\mathrm{c}}$ e $\mathrm{N}_{\mathrm{v}}$ costumam ser da ordem de $10^{19} \mathrm{~cm}^{-3}$, de modo que quando a excitação térmica é o único mecanismo de geração de transportadores de carga, $[\mathrm{n}]=[\mathrm{p}]$ e a concentração total de transportadores decai fortemente com o aumento da energia de Band Gap para uma dada temperatura. A exemplo disso, em temperatura ambiente $(298,15 \mathrm{~K})$, o produto $\mathrm{kT}$ é de $0,0257 \mathrm{eV}$, o que para os valores propostos acima indica a classificação de isolante para materiais com Eg a partir de $0,5 \mathrm{eV} \cdot{ }^{14}$ Sendo assim, não é surpreendente que à temperatura ambiente semicondutores intrínsecos apresentem um número limitado de aplicações por sua baixa condutividade. Ao determinar na prática ${ }^{15}$ a população de elétrons excitados em semicondutores intrínsecos típicos, como o $\mathrm{Si}$ ou o GaAs, é possível encontrar valores no intervalo entre $10^{6}$ e $10^{10} \mathrm{~cm}^{-3}$, o que se compara desfavoravelmente ao número de transportadores livres disponíveis em metais, que chega a ordem de $10^{28} \mathrm{~cm}^{-3}$. Portanto, o aumento de condutividade do material é essencial, havendo algumas estratégias para isso. A mais comum é a dopagem.

A dopagem consiste na adição (por difusão em fornos ou por implantação de íons) de uma concentração muito baixa de átomos com um elétron de valência a mais ou a menos do que o elemento do qual é constituído o semicondutor (p. ex., respectivamente, $\mathrm{P}$ ou B para o $\mathrm{Si}$ ) em sua rede cristalina, havendo a substituição. Semicondutores dopados com elementos com elétrons a mais na camada de valência são chamados de semicondutores extrínsecos do tipo $n$, enquanto que os dopados com elementos com um déficit de elétrons são chamados semicondutores extrínsecos tipo $p .{ }^{15}$

Nos semicondutores do tipo $n$, como os elétrons excedentes encontram-se fracamente ligados aos seus átomos dopantes parentais (energia de ligação da ordem de décimos de eV), eles geralmente são facilmente ionizados e promovidos para a Banda de Condução, sendo representados em um diagrama de bandas na forma de uma linha pontilhada ou uma sub-banda doadora localizada cerca de $0,1 \mathrm{eV}$ abaixo da BC (Figura 3). Isso não significa que estados eletrônicos acessíveis foram gerados no meio do Band Gap, mas sim aponta para a existência de elétrons que podem ser muito facilmente levados a estados que permitem transporte de carga. É importante ressaltar que os transportadores de carga majoritários aqui são os elétrons ( $\left.\mathrm{e}^{-}\right)$. Nos semicondutores do tipo $p$, a inserção de níveis aceptores de elétrons pela introdução de átomos com um elétron de valência a menos induz ao transporte de carga majoritário por lacunas $\left(\mathrm{h}^{+}\right)$, de modo que esses níveis são representados por uma sub-banda receptora logo acima da banda de valência ${ }^{15}$ (Figura 3).

Como representado na Figura 3, a posição do nível de Fermi $\left(\mathrm{E}_{\mathrm{f}}\right)$ observada no semicondutor intrínseco é deslocado de acordo com o tipo de dopagem. À temperatura ambiente, o nível de Fermi encontra-se aproximadamente na metade do Band Gap. Mantendo-se a temperatura constante, o nível de Fermi se desloca linearmente em função do logaritmo da densidade de dopagem seguindo no sentido de valores mais próximos da borda da banda de condução para o tipo $n$ e da de valência para o tipo $p .{ }^{14-16} \mathrm{~A}$ distância do $\mathrm{E}_{\mathrm{f}}$ à borda da banda adjacente é um fator importante para determinar a concentração do transportador majoritário ([n] ou [p]), como mostrado a seguir nas Eqs. 4 e 5, deduzidas a partir da Eq. 3.

$$
\begin{aligned}
& {[n]=N_{c} e^{\frac{-\left(E_{c}-E_{f}\right)}{k T}}} \\
& {[n]=N_{v} e^{\frac{-\left(E_{f}-E_{v}\right)}{k T}}}
\end{aligned}
$$

Do ponto de vista matemático, ao elevar a concentração de um

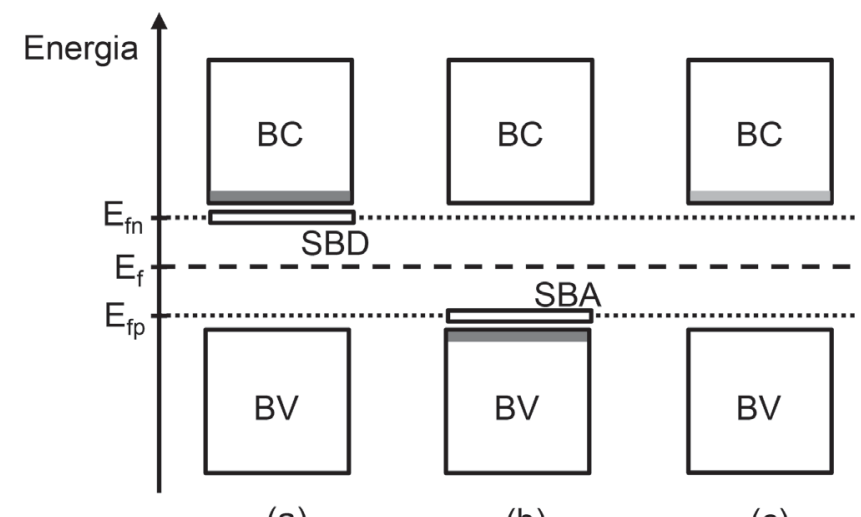

(a)

(b)

(c)

Figura 3. Representação esquemática de um diagrama de bandas para semicondutores extrínsecos (a) do tipo n e (b) p em comparação a (c) um intrínseco. BC: banda de condução; BV: banda de valência; $E_{f}$ : nível de Fermi do semicondutor intrínseco; $E_{f n}$ : nível de Fermi do semicondutor $n ; E_{f p}$ : nível de Fermi do semicondutor p; SBD: sub-banda doadora; SBA: sub-banda aceptora. Diagrama esquemático representado à temperatura ambiente $(\approx 298,15$ K). Sombreamento cinza gradual apontando a presença de níveis acessiveis para transporte de carga

dos transportadores de carga através da dopagem n ou p ([n] ou [p]), os termos que se alteram na igualdade para acompanhar esse aumento são as diferenças $\left(E_{c}-E_{f}\right)$ ou $\left(E_{f}-E_{v}\right)$ e, quando essa diferença se aproxima de 0 (mais precisamente cerca de $0,1 \mathrm{eV}$ referente à energia de ionização/associação dos elétrons com os átomos/íons dopantes), a concentração de transportadores se iguala à densidade de estados nas bordas da banda mais próxima, chegando ao limite máximo de condutividade do material como um semicondutor. Por isso, raramente se excede o limite de concentração de dopantes da ordem de $10^{19} \mathrm{~cm}^{-3}$. Como a energia de ativação dos elétrons aos níveis que permitem o transporte de carga é muito baixa, no estado de equilíbrio termodinâmico, a concentração do transportador majoritário é praticamente igual à concentração do dopante em temperatura ambiente. Assim, ao ultrapassar o limite de dopagem citado, o semicondutor inicia a chamada degeneração, em que o nível de Fermi adentra a banda adjacente e o material se torna um quase-condutor, perdendo suas características. ${ }^{14}$ Essa estratégia é especificamente utilizada em aplicações em que se deseja estipular contato ôhmico (não-retificado) entre um condutor e um semicondutor, como em contatos elétricos de dispositivos eletrônicos.

É importante ressaltar que, mesmo sob qualquer um dos tipos de dopagem, ainda há transportadores provindos da semicondução intrínseca, porém, com uma contribuição muito baixa frente aos transportadores introduzidos pela impureza dopante em temperatura ambiente, principalmente por parte dos transportadores de carga inversa à da dopagem (p. ex., $\mathrm{h}_{\mathrm{BV}}^{+}$em dopagem $\mathrm{n}$ ).

A contribuição dos transportadores intrínsecos para a condutividade do material dopado pode aumentar com a temperatura do sistema e até se tornar majoritária em casos extremos, deslocando o nível de Fermi das vizinhanças da banda novamente para o centro do Band Gap $^{15,16}$ (Figura 3). Isso ocorre pela transição do mecanismo gerador de transportadores majoritários, que passa de um controle pelo grau de ionização dos dopantes a baixas temperaturas (ambiente) à transferência térmica dos transportadores da $\mathrm{BV}$ à $\mathrm{BC}$ em elevadas temperaturas. ${ }^{16}$

\section{TRANSIÇÕES ELETRÔNICAS ENTRE BANDAS}

Como mencionado anteriormente, em um semicondutor a banda de condução (BC) encontra-se predominantemente vazia, enquanto a 
banda de valência (BV) encontra-se cheia. Além da estratégia apontada de dopagem, a condutividade deste tipo de material pode ser aumentada através de uma perturbação externa, como, por exemplo, a absorção de fótons com energia igual ou superior ao Band Gap para a promoção de elétrons à $\mathrm{BC}$, deixando lacunas na $\mathrm{BV} .{ }^{14}$

A lacuna é uma quasipartícula que pode, assim como o elétron, ser descrita em termos de carga $\left(\mathrm{e}^{+}\right)$, spin $(\mathrm{s}=1 / 2)$ e massa efetiva $\left(\mathrm{m}_{\mathrm{ef}}\right)$. A massa efetiva é uma grandeza para contabilização do efeito da interação da partícula com a rede cristalina na sua mobilidade. Valores superiores à massa do elétron livre no vácuo representam partículas com mobilidade retardada pela interação com a rede, enquanto valores inferiores representam um incremento de mobilidade. Paralelamente, a massa efetiva também pode ser um representativo da extensão espacial da função de onda da partícula no material, de modo que massas efetivas menores representam alta deslocalização do transportador. ${ }^{17}$

O par elétron/lacuna $\left(\mathrm{e}^{-}{ }_{\mathrm{BC}} / \mathrm{h}^{+}{ }_{\mathrm{BV}}\right)$, formado por excitação eletrônica, interage por força de Coulomb devido às respectivas cargas opostas, podendo ser tratado unitariamente como uma quasipartícula: o éxciton. ${ }^{18} \mathrm{~A}$ formação do éxciton envolve uma quantidade mínima de energia (Eg), assim como também requer a conservação de momento (Figura 4)..$^{18,19}$

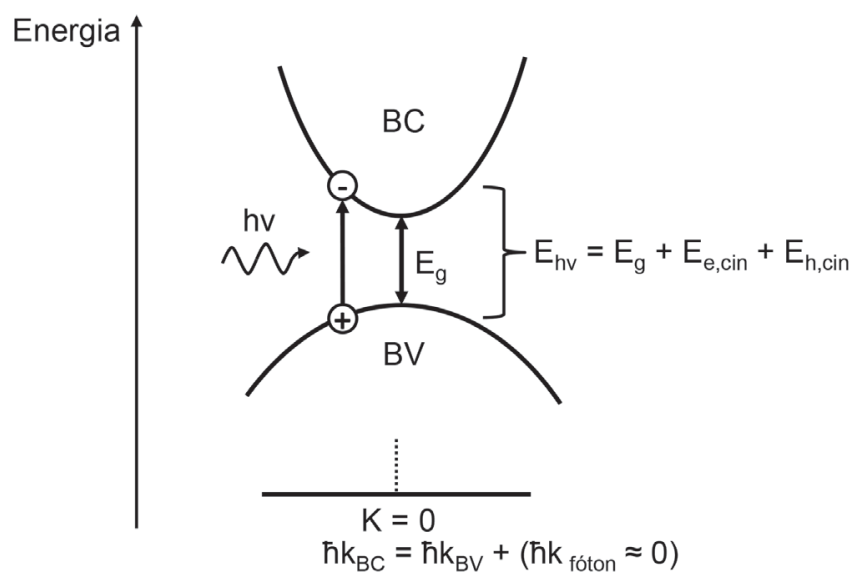

Figura 4. Representação esquemática da transição eletrônica direta de um elétron da banda de valência $(B V)$ à banda de condução $(B C)$ em um semicondutor de Band Gap direto. $E_{h v}=$ energia do fóton; $E_{g}=$ Band Gap; $E_{e, c i n}=$ energia cinética do elétron na banda de condução; $E_{h, \text { cin }}=$ energia cinética da lacuna na banda de valência; $\hbar$ constante reduzida de Planck $(\hbar=h / 2 \pi) ; k_{B C}, k_{B V}$ e $k_{\text {fóton }}=$ vetor de onda do elétron na banda de condução, da lacuna na banda de valência e do fóton. Adaptado da tese de Groeneveld ${ }^{20}$

A energia quantizada do fóton pode caracterizar o éxciton formado em "quente" ou "frio", sendo que fótons com energia superior ao Band Gap induzem a excitação do elétron a orbitais acima da borda de fundo da BC, como também geram lacunas mais profundas abaixo da borda de topo da BV, conferindo aos elétrons mobilidade interorbital nas bandas que se caracteriza como a energia cinética do transportador fotogerado $\left(\mathrm{E}_{\mathrm{e}, \text { cin }}\right.$ ou $\mathrm{E}_{\mathrm{h}, \text { cin }}$ da Figura 4). A transição também deve ser acompanhada da manutenção do momento do sistema e, como o fóton apresenta momento $p$ desprezível $\left(\approx 10^{-28}\right)$, o vetor de onda $\mathrm{k}$ da BC deve coincidir com o da BV para que seja observada uma transição direta. ${ }^{18,19}$ Daí deriva-se o conceito de Band Gap direto e indireto. ${ }^{15,21}$

$\mathrm{O}$ Band Gap direto é aquele em que o vetor de onda do nível mais alto da BV coincide com o vetor de onda do nível mais baixo da BC, permitindo a transição direta apenas pela absorção de fótons (quando satisfeitas as regras ópticas de permissão de transição). Quando os níveis mencionados das bandas não coincidem no mesmo momento, o processo de fotoexcitação depende também da interação do elétron com um fônon (quantum de vibração da rede cristalina) para transferência de momento, reduzindo a probabilidade de ocorrência do fenômeno. ${ }^{15,21}$ Em termos práticos, o coeficiente de absorção de semicondutores com Band Gap indireto apresenta ganhos menos acentuados com o aumento da energia dos fótons para fotoexcitação e exigem, mesmo para comprimentos de onda consideravelmente menores do que o equivalente ao Band Gap, espessuras de filme maiores para um bom aproveitamento da radiação incidente. ${ }^{14}$

$$
\alpha=\frac{A(h v-E g)^{\frac{m}{2}}}{h v}
$$

Na Eq. 6, $\alpha$ representa o coeficiente de absorção, A uma constante, $\mathrm{m}=1$ para uma transição de Band Gap direta, $\mathrm{m}=4$ para transição de Band Gap indireta, h é a constante de Planck e $v$ é a frequência da radiação incidente.

Como anteriormente mencionado, o excesso de energia de um fóton em relação ao Band Gap do material pode caracterizar a formação de um éxciton quente, em que os elétrons e lacunas ocupam estados excitados da BC e BV, respectivamente. Neste caso, ambos tendem a relaxar para que o éxciton decaia para o seu estado fundamental através de etapas rápidas de relaxação intrabanda não-radiativas, liberando o excesso de energia na forma de calor. ${ }^{17,22}$ Como essas transições não são restritas por regras de seleção, elas ocorrem em intervalos muito curtos $(<1 \mathrm{ps})$, seja pelo acoplamento à um fônon de energia compatível ou pela transferência de energia entre transportadores de carga pelo espalhamento Auger. ${ }^{22,23}$

Uma vez que o éxciton tenha atingido o estado fundamental, qualquer relaxação adicional deve ocorrer pela recombinação do par $\mathrm{e}^{-}{ }_{\mathrm{BC}} / \mathrm{h}^{+}{ }_{\mathrm{BV}}$, havendo o retorno do elétron da BC para a BV. A energia relativa a essa transição (igualmente sujeita às regras de seleção como a excitação) pode ser liberada radiativamente (com emissão de fóton) ou por processo não-radiativo. ${ }^{19}$

A emissão radiativa pode ocorrer sob influência de gatilho de uma frequência ressonante à transição eletrônica de retorno, a chamada emissão estimulada, comum na emissão de radiação coerente em LASERs; ou ainda pode ocorrer de modo espontâneo, mediante combinação linear dos orbitais do estado fundamental e excitado por flutuações de vácuo ou modos de vácuo, apresentando dependência com a amplitude de momento de dipolo da transição, com a frequência da radiação de excitação e, principalmente, com a densidade de modos ópticos acoplados à transição de retorno. ${ }^{17}$

A recombinação não-radiativa geralmente está condicionada à presença de defeitos ou impurezas na composição do semicondutor, uma vez que requer o acoplamento com um número muito elevado de fônons. Por outro lado, defeitos na rede cristalina ou ainda alguns estados presentes na superfície do semicondutor são capazes de gerar os chamados traps, os quais reduzem a sobreposição de fases das funções de onda dos transportadores entre si, induzindo ao quenching da emissão e viabilizando a relaxação não-radiativa por acoplamento com vibrações locais (fônons). É importante ressaltar que a recombinação radiativa, mesmo com menor probabilidade, ainda pode ocorrer com o éxciton em trap, porém a energia do fóton emitido é mais baixa ( $\lambda$ maior) e o rendimento quântico do processo é bastante limitado. ${ }^{17} \mathrm{Um}$ último caso de recombinação não-radiativa própria de Quantum Dots $(\mathrm{d}<6 \mathrm{~nm})$ é a transferência da energia do éxciton entre diferentes partículas, ${ }^{24}$ de modo que um QD doador sofre uma recombinação e através de uma interação dipolo-dipolo é capaz de induzir um éxciton em um $Q D$ aceptor. Abaixo seguem sumarizados os diferentes tipos de recombinação discutidos (Figura 5).

Um dos principais supressores da recombinação, mesmo na ausência de aceptores eletrônicos, é o fenômeno anteriormente mencionado de trapping. Um trap (armadilha) é uma região espacial do 


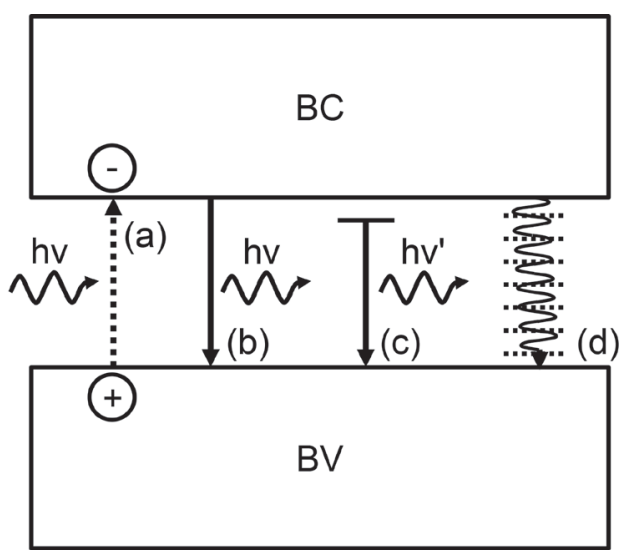

Figura 5. Ilustração esquemática apresentando os diferentes tipos de recombinação de transportadores de cargas vista em semicondutores: (a) excitação; (b) recombinação radiativa (c) recombinação radiativa assistida por um defeito ou estado superficial ( $\left.v>v^{\prime}\right)$; (d) recombinação não-radiativa. Adaptado da tese de Groeneveld ${ }^{20}$

cristal em que o transportador de carga $\left(\mathrm{e}^{-}{ }_{\mathrm{BC}} \mathrm{Ou} \mathrm{h}^{+}{ }_{\mathrm{BV}}\right.$ em semicondutores) se move para ganho de energia livre do sistema, atingindo um mínimo de potencial eletroquímico. Há uma boa relação de energia a um trap que, se muito profundo, pode comprometer o potencial de oxidação e/ou redução de lacunas e elétrons, respectivamente, podendo também inibir o transporte ou a transferência de carga. Se muito raso, os efeitos de supressão de recombinação são bastante reduzidos, elevando a probabilidade de emissão de fótons (Figura 5c) ou calor e limitando a energia efetiva acumulada nos estados para os processos fotocatalíticos. O resultado disso é a inibição cinética das reações químicas adjacentes. ${ }^{25} \mathrm{O}$ fenômeno de trapping costuma ser bastante benéfico quando localizado na superfície do material, região onde há interesse em suprimir a recombinação e elevar a localização dos transportadores na interface para captura por espécies químicas (reações interfaciais). Muitos são os parâmetros que podem regular os estados de trap superficiais, dentre eles a estrutura local (defeitos), a presença de adsorbatos e a aplicação de potencial por sistemas eletroquímicos. ${ }^{25,26}$

Igualmente aos traps, o fenômeno de space-charge layer ou, mais precisamente, a sua modulação pela aplicação de potencial por sistemas eletroquímicos, é capaz de suprimir eficientemente a recombinação $\mathrm{e}_{\mathrm{BC}}^{-} / \mathrm{h}^{+}{ }_{\mathrm{BV}}$ pela separação espacial desses transportadores. Ao operar em células fotoeletroquímicas, há sempre a formação de uma interface semicondutor/eletrólito, região onde se faz mais relevante a supressão da recombinação para obtenção de maior número de transportadores e, consequentemente, maiores velocidades de transferência de carga com o eletrólito. Segue o tratamento desse modelo importante.

\section{O MODELO DE SPACE-CHARGE LAYER}

A space-charge layer (SCL) é um fenômeno essencial para a separação de cargas em interfaces de semicondutores, além de representar o principal modelo para caracterização do comportamento de retificação em junções p-n e eletrólito/semicondutor. Essencialmente ela apresenta quatro modelos de conformação (Figura 6).

Na Figura 6, aplicou-se como exemplo a interface de um semicondutor do tipo $\mathrm{n}$ (dopado) com um suposto eletrólito de suporte contendo uma espécie aceptora (eletroativa) de potencial redox formal E' ${ }^{27}$ Quando ambos são colocados em contato, uma corrente flui através da junção até que o equilíbrio seja atingido no momento em que o nível de Fermi do semicondutor $\left(\mathrm{E}_{\mathrm{f}}\right)$ e o potencial redox da espécie aceptora no eletrólito (E') se igualam. E' é simplesmente um

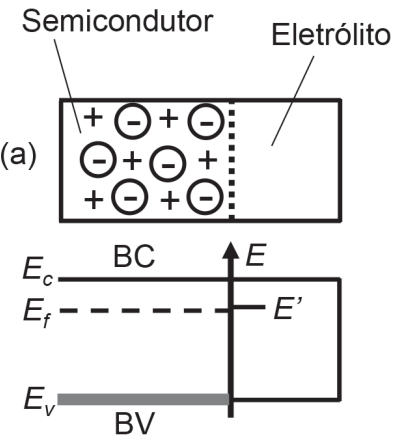

Potencial de Bandas Planas

(c)
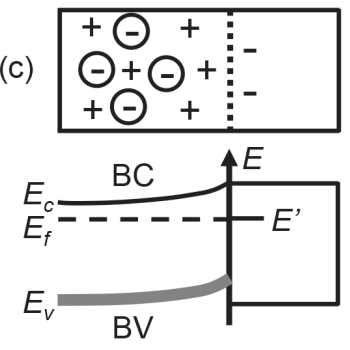

Camada de Esgotamento (b)
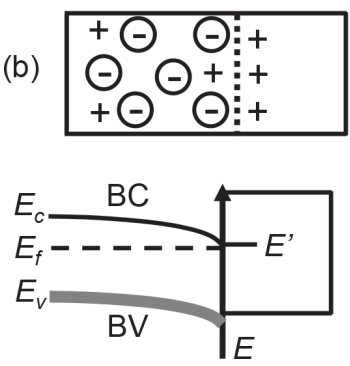

Camada de Acumulação

(d)
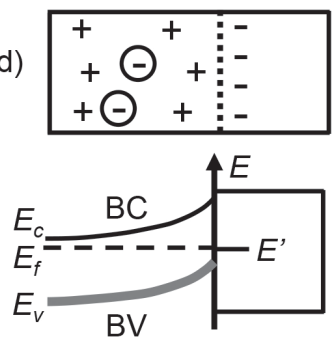

Camada de Inversão

$$
\Theta \mathrm{e}_{\mathrm{BC}}^{-}+\text {Dopante lonizado - Ânions do Eletrólito }
$$

Figura 6. Diagrama esquemático de visão pictorial do modelo de space- charge layer desenvolvido na interface de um semicondutor do tipo n com um eletrólito de suporte contendo espécies aceptoras dos elétrons proveniente da sua banda de condução $\left(e_{B C}^{-}\right)$e os respectivos diagramas de bandas à temperatura ambiente $(298,15 \mathrm{~K})$ de acordo com o caso: (a) potencial de bandas plano; (b) camada de acumulação; (c) camada de esgotamento; (d) camada de inversão. Todos os sistemas foram representados em equilíbrio $\left(E_{f}=E^{\prime}\right)$. BC: banda de condução; $B V$ : banda de valência; $E^{\prime}$ : potencial formal do par redox da espécie eletroativa no eletrólito; $E_{c}$ : potencial da banda de condução; $E_{v}$ : potencial da banda de valência. Adaptado do trabalho de insight de Grätzel $^{27}$

potencial Nernstiano e representa “o nível de Fermi” do eletrólito em uma analogia em que o estado ocupado é representado pela espécie reduzida e o estado vacante pela espécie oxidada. A velocidade com que o equilíbrio é alcançado depende da velocidade de transferência de carga do material e costuma ser mais lenta para semicondutores do que para metais. ${ }^{14} \mathrm{Na}$ interface do eletrólito, o carregamento interfacial se constitui na dupla camada elétrica, composta pela zona compacta (modelo de Helmholtz) e pela zona difusa (modelo de Gouy-Chapman). Do lado do semicondutor na junção, o arqueamento de banda (Band Bending) depende da posição do nível de Fermi, de modo que se ele se igualar ao potencial de banda plana $\left(\mathrm{E}_{\mathrm{f}}=\mathrm{E}^{\prime}=\mathrm{E}_{\mathrm{FB}}\right)$, não se observa a formação de space-charge layer e, portanto, o potencial relativo às bandas permanece plano desde a região de bulk até a interface (Flat Band Potential - Figura 6a). ${ }^{27}$

$$
E_{B}=E_{f}-E^{\prime}
$$

em que "E $E_{\mathrm{B}}$ " é o potencial (ou energia) de arqueamento de banda (Band Bending), "E $\mathrm{E}_{\mathrm{f}}$ " é o potencial relativo ao nível de Fermi, E' é o potencial formal desenvolvido pela espécie eletroativa na interface. Caso haja acúmulo de elétrons pelo lado do semicondutor na interface e a indução de carregamento positivo na dupla-camada elétrica, observa-se a formação da camada de acumulação (Figura 6b). Por outro lado, se os elétrons forem esgotados na interface do semicondutor, 
cargas positivas imóveis provindas dos estados doadores ionizados do dopante (semicondutor tipo n) são deixadas para trás, havendo a formação da camada de esgotamento (Figura 6c) com carregamento negativo da dupla camada elétrica. Caso o esgotamento de elétrons prossiga a uma extensão com concentração inferior ao nível intrínseco, a superfície adquire caráter p (excesso de cátions imóveis do dopante) frente ao bulk do material, sendo possível a formação da camada de inversão (Figura 6d). ${ }^{27}$

$\mathrm{O}$ potencial de banda plana $\left(\mathrm{E}_{\mathrm{FB}}\right)$ é um parâmetro importante para ser determinado por auxiliar na determinação do nível de Fermi e, consequentemente, no potencial da banda de condução. ${ }^{27}$ Sua determinação pode ser feita pela medida da capacitância da junção semicondutor-eletrólito em potenciais crescentes para polarização reversa da junção, na qual o modelo de Mott-Schottky se aplica. ${ }^{28}$

$$
\frac{1}{C_{S C}{ }^{2}}=\frac{2\left(\frac{\Phi_{S C} R T}{F}\right)}{\varepsilon \varepsilon_{0}{ }^{1} N}
$$

em que $\mathrm{C}_{\mathrm{SC}}$ é a capacitância medida, $\Phi_{\mathrm{SC}}$ é o decaimento de potencial observado na space-charge layer $\left(\Phi_{\mathrm{SC}}=\mathrm{V}-\mathrm{V}_{\mathrm{FB}}\right)$, R é a constante universal dos gases $\left(8,314 \mathrm{~J} \mathrm{~K}^{-1} \mathrm{~mol}^{-1}\right)$, $\mathrm{T}$ a temperatura absoluta em Kelvin, $\mathrm{F}$ a constante de Faraday $\left(96485 \mathrm{C} \mathrm{mol}^{-1}\right), \varepsilon$ a constante dielétrica do semicondutor, $\varepsilon_{0}$ a permissividade no vácuo e ${ }^{1} \mathrm{~N}$ é a concentração de dopante ionizado. Há tanto a capacitância da space-charge layer $\left(\mathrm{C}_{\mathrm{SCL}}\right)$ como da camada de Helmholtz $\left(\mathrm{C}_{\mathrm{H}}\right)$ a serem consideradas, sendo que ambas podem ser ponderadas como em série, em analogia a circuitos eletrônicos. No regime de esgotamento (Figura 6c) $\mathrm{C}_{\mathrm{SCL}}<\mathrm{C}_{\mathrm{H}} \mathrm{e}$, portanto, a capacitância medida é predominantemente característica da space-charge layer. Ao plotar os valores do recíproco do quadrado da capacitância com o potencial de polarização reversa aplicado, obtém-se uma relação linear, a qual, ao ser extrapolada ao ponto $1 / \mathrm{C}_{\mathrm{SC}}{ }^{2}=0$, revela o valor de potencial de banda plana $\left(\mathrm{E}_{\mathrm{FB}}\right){ }^{27,29}$ Como nesse ponto nulo do recíproco do quadrado da capacitância em que o $\mathrm{E}_{\mathrm{FB}}$ é atingido, também $\mathrm{E}_{\mathrm{B}}=0$ (banda plana), o nível de Fermi se iguala ao potencial redox da espécie eletroativa em solução e corresponde, aproximadamente, ao potencial da banda de condução para semicondutores n suficientemente dopados a 298,15 K (Eq. 7). Por isso, o potencial de banda plana exprime, para semicondutores $\mathrm{n}$, o poder redutor dos elétrons na banda de condução e permite avaliar termodinamicamente a viabilidade de reações de redução no material de acordo com o potencial do par redox (E') em solução. Conhecendo-se a energia de Band Gap (Eg), é possível igualmente determinar o potencial das lacunas na banda de valência $\left(\mathrm{E}_{\mathrm{BV}}=\mathrm{E}_{\mathrm{BC}}\right.$ $+\mathrm{Eg}$ ) e, através da comparação com o potencial redox formal de solutos intencionados, estimar seu poder oxidante. ${ }^{28} \mathrm{~A}$ junção dos dados de potencial das bandas de valência e condução juntamente ao Band Gap gera um diagrama de posição de bandas (Figura 7), extremamente útil para a seleção do material mais adequado para as aplicações químicas desejadas. ${ }^{27}$

Semicondutores com potencial da banda de valência alto (p. ex. $\mathrm{TiO}_{2}, \mathrm{WO}_{3}$ e $\mathrm{ZnO}$ ) apresentam lacunas com elevado poder oxidante, além de boa estabilidade à corrosão e fotocorrosão. Mas, geralmente, esses semicondutores apresentam Band Gap dentro da faixa UV $(\mathrm{Eg}=3,2 \mathrm{eV} \approx 390 \mathrm{~nm}$ ), o que reduz a eficiência de aplicações com aproveitamento do espectro solar como fonte de radiação. Quanto maior for o poder redutor e oxidante simultaneamente de um semicondutor, mais distantes são suas bandas, maior o seu caráter isolante e menores os comprimentos de onda requeridos para promover sua fotoexcitação.

Outro parâmetro importante é o potencial de arqueamento de bandas $\left(\mathrm{E}_{\mathrm{B}}\right)$ que corresponde ao fotopotencial de circuito aberto. ${ }^{27}$ Para a reação apontada na Figura 7 de decomposição da água, o par

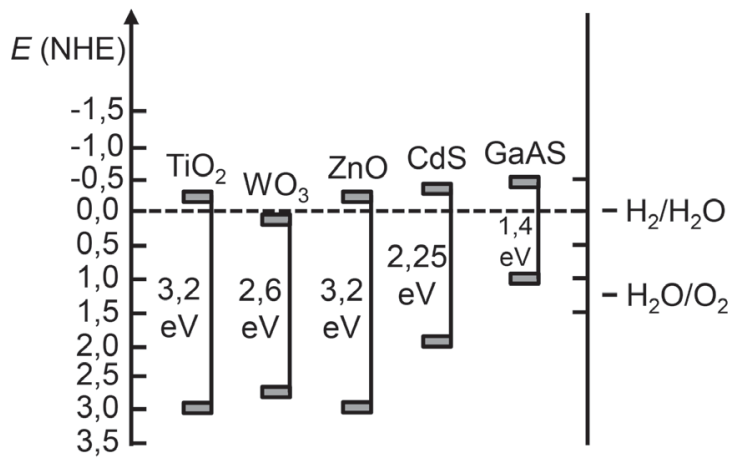

Figura 7. Diagrama de posição de bandas para alguns exemplos de semicondutores apresentando as respectivas posições em $V$ frente ao eletrodo normal de hidrogênio (NHE) em $\mathrm{pH}=1$, o Band Gap de cada material (eV) e a posição do potencial padrão (vs. NHE) de um exemplo de reações redox para a decomposição da água em hidrogênio e oxigênio. Adaptado do trabalho de insight de Grätzel ${ }^{27}$

redox do eletrólito para um fotoanodo é o $\mathrm{O}_{2} / \mathrm{H}_{2} \mathrm{O}$, com potencial de $1,23 \mathrm{~V} v$ s. NHE. Para que a eletrólise da água seja realizada puramente pela ação da luz incidente, $\mathrm{E}_{\mathrm{B}}$ deve exceder $1,23 \mathrm{~V}$, de modo que a banda de condução $\left(\mathrm{E}_{\mathrm{BC}} \approx \mathrm{E}_{\mathrm{f}}\right)$ se situe no mínimo 1,23 V abaixo do par $\mathrm{O}_{2} / \mathrm{H}_{2} \mathrm{O}$ e, portanto, abaixo do par $\mathrm{H}^{+} / \mathrm{H}_{2} \cdot{ }^{28}$ Caso essa circunstância não possa ser atingida apenas pela ação da luz, é possível ainda aplicar um potencial em um suposto substrato condutor utilizado como leito do filme semicondutor. Daí consolida-se um dos papeis do potencial de polarização $\left(\mathrm{E}_{\text {bias }}\right)$ nesses eletrodos: caso $\mathrm{E}_{\mathrm{B}}$ (fotopotencial) seja menor do que o potencial do par redox do eletrólito (mais a sobretensão), $\mathrm{E}_{\text {bias }}$ pode completar a demanda energética restante. ${ }^{28}$ No exemplo da eletrólise da água sob irradiação em fotoânodos de $\mathrm{TiO}_{2}$, a luz permite eletrolisar a água em aproximadamente $+0,2 \mathrm{~V} v s$. $\mathrm{NHE},{ }^{28}$ mais de 1,0 V abaixo do potencial termodinâmico exigido, mas ainda com a necessidade do complemento elétrico para a efetivação da reação. Este é considerado, conceitualmente, o verdadeiro efeito fotoeletrocatalítico, em que a luz é capaz de reduzir (ou extinguir) a tensão termodinâmica e a sobretensão elétricas exigidas para a efetivação de uma reação, ainda com cinética mensurável.

Um segundo papel da aplicação de potencial de polarização ao substrato condutor consiste em influenciar a cinética da reação interfacial através do aumento da disponibilidade de um dos transportadores na interface. Nessa função, a velocidade e até a natureza do processo Faradaico (anódico ou catódico) tornam-se dependentes do potencial aplicado $\left(\mathrm{E}_{\text {bias }}\right) .{ }^{14}$ Este efeito é totalmente explicado utilizando os modelos de space-charge layer apresentados na Figura 6. Por simplificação, inicialmente, o efeito do potencial será tratado na ausência de luz na forma de um processo eletroquímico no escuro. Em seguida, serão tratados os processos sob a incidência de luz.

\section{MODULAÇÃO DA SPACE-CHARGE LAYER}

A aplicação de um potencial para polarização do substrato afeta a posição das bordas das bandas de valência e condução e, de acordo com o seu arqueamento (band bending), observam-se as diferenças de natureza das reações interfaciais. Primeiramente, ao aplicar um potencial constante pode-se observar a formação de três regiões com potencial elétrico variável: a space-chage layer na interface do semicondutor, a zona compacta e a difusa da dupla camada elétrica. Ao operar com concentrações suficientemente elevadas de eletrólito de suporte $\left(>0,1 \mathrm{~mol} \mathrm{~L}^{-1}\right)$, a espessura da zona difusa se torna muito baixa ( $\approx 10$ Angstroms) e o potencial que decai através dela pode ser negligenciado, permitindo assumir que todo o potencial deve decair somente através da space-charge layer e da camada de Helmholtz. De 
acordo com o princípio da soma de capacitores em séries $\left(1 / \mathrm{C}_{\mathrm{T}}=1 /\right.$ $\mathrm{C}_{\mathrm{SCL}}+1 / \mathrm{C}_{\mathrm{H}}$ ), o lado da interface que apresenta o menor número de transportadores de carga sofre as maiores mudanças com a modulação de potencial e, de acordo com os níveis típicos de dopagem (no intervalo entre $10^{15} \mathrm{e} 10^{19} \mathrm{~cm}^{-3}$ ), o semicondutor apresenta algumas ordens de grandeza a menos de transportadores do que eletrólitos fortes em meio aquoso $\left(\approx 10^{20} \mathrm{~cm}^{-3}\right.$ para concentração $0,1 \mathrm{~mol} \mathrm{~L} \mathrm{~L}^{-1}$ de um sal de estequiometria 1:1). Portanto, a modulação de potencial afeta predominantemente a distribuição de carga interfacial do semicondutor e, consequentemente, o arqueamento de bandas. ${ }^{14}$

A diferença de potencial observada na space-charge layer é produto da distribuição desigual dos transportadores majoritários (elétrons ou lacunas), como também dos sítios carregados provindos dos dopantes, observando-se uma variação suave do potencial através de sua extensão. $\mathrm{O}$ arqueamento se deve à diferença gradual de energia dos elétrons em regiões de potencial elétrico variável, o que confere um caráter positivo ou negativo de curvatura à borda das bandas. A magnitude do arqueamento é igual ao decaimento de potencial através da SCL e uma consequência importante disso é a perturbação das concentrações dos elétrons e lacunas na interface frente ao bulk. O nível de Fermi permanece constante sob essa circunstância e o arqueamento induz a uma mudança na distância relativa das bordas das bandas ao $\mathrm{E}_{\mathrm{f}}$, o que, de acordo com as Eqs. 4 e 5, leva ao acúmulo de um tipo de transportador e o esgotamento daquele de carga oposta. Para o caso de arqueamento positivo, elétrons tendem ao esgotamento na interface e lacunas ao acúmulo; para arqueamento negativo, elétrons tendem ao acúmulo na interface enquanto lacunas ao esgotamento. ${ }^{14}$

Para a determinação do arqueamento das bandas, um parâmetro novamente importante é o potencial de banda plana $\left(\mathrm{E}_{\mathrm{FB}}\right)$, além do tipo de semicondutor utilizado. Em um semicondutor intrínseco (Figura 8), a aplicação de potencial acima dele $\left(\mathrm{E}_{\mathrm{bias}}>\mathrm{E}_{\mathrm{FB}}\right)$ gera um arqueamento de bandas positivo, com afastamento da Banda de Condução e aproximação da Banda de Valência ao nível de Fermi, indício de leve acúmulo de lacunas $\left(\mathrm{h}^{+}{ }_{\mathrm{BV}}\right)$ na interface. A aplicação de potencial abaixo dele $\left(\mathrm{E}_{\mathrm{bias}}<\mathrm{E}_{\mathrm{FB}}\right)$ leva ao arqueamento negativo, aproximando a Banda de Condução e afastando a Banda de Valência do nível de Fermi, o que significa um leve acúmulo de elétrons na interface (Figura 8). Esse processo leva à separação espacial de cargas, acumulando um tipo de transportador na interface do eletrodo de trabalho.

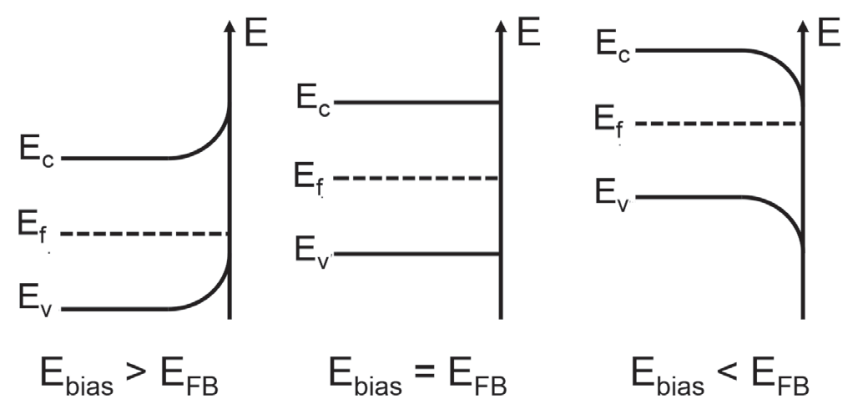

Figura 8. Fenômeno de arqueamento de bandas (band bending) para um semicondutor intrínseco sob diferentes condições de polarização pela aplicação de um potencial externo no substrato condutor. $E_{\text {bias: }}$ : potencial de polarização do substrato; $E_{F B}$ : potencial de banda plana; $E_{f}$ : nível de Fermi; $E_{V}$ : potencial da borda da banda de valência; $E_{C}$ : potencial da borda da banda de condução. Adaptado da obra FINKLEA ${ }^{14}$

De fato, como o nível de Fermi em um semicondutor intrínseco encontra-se no meio do Band Gap, a polarização até pode induzir ao arqueamento e leve acúmulo de carga na interface, mas mesmo quando $\mathrm{E}_{\text {bias }} \gg \mathrm{E}_{\mathrm{FB}}$ ou $\mathrm{E}_{\text {bias }}<<\mathrm{E}_{\mathrm{FB}}$, todos os efeitos práticos são dependentes do Band Gap (Eg) e, portanto, dos níveis intrínsecos de transportadores que costumam ser baixos para $\mathrm{Eg}>0,5 \mathrm{eV}$. Entretanto, caso o semicondutor intrínseco seja livre de estados superficiais, absolutamente todo o potencial aplicado diferente do $\mathrm{E}_{\mathrm{FB}}$ é aproveitado no fenômeno de arqueamento de bandas e essa condição interessante pode ser extrapolada a semicondutores extrínsecos $p$ e $n \cdot{ }^{14}$

Em um semicondutor extrínseco, a magnitude do potencial aplicado é de suma importância para a caracterização do modelo de SCL desenvolvido. Ao polarizar levemente o substrato com $\mathrm{E}_{\mathrm{bias}}>\mathrm{E}_{\mathrm{FB}}$ em um semicondutor $\mathrm{n}$, ambas as bandas sofrem um arqueamento positivo de modo que a $\mathrm{BC}$ se distancia do $\mathrm{E}_{\mathrm{f}}$ e a $\mathrm{BV}$ se aproxima. Mas, como o nível de Fermi ainda se encontra bastante distante da BV mesmo após o arqueamento, o que realmente se observa é o esgotamento de transportadores na interface, formando a camada de esgotamento (Figura 6C). O mesmo pode-se dizer de um semicondutor p levemente polarizado negativamente $\left(\mathrm{E}_{\mathrm{bias}}<\mathrm{E}_{\mathrm{FB}}\right)$, com a diferença de que se observa um arqueamento negativo com afastamento da $B V$ do $E_{f} e$ leve aproximação da $\mathrm{BC} .{ }^{14}$ Sob esse modelo de esgotamento, além de ser possível a determinação do $\mathrm{E}_{\mathrm{FB}}$ através do modelo de MottSchottky como anteriormente descrito (Eq. 8) é possível estimar a espessura (W) da SCL:

$$
W=\sqrt{\frac{2 \varepsilon \varepsilon_{0}\left|E_{\text {bias }}-E F_{B}\right|}{q N_{d}}}
$$

em que $\mathrm{N}_{\mathrm{d}}$ é o nível de dopante, $\varepsilon$ é a constante dielétrica na direção normal à superfície, $\varepsilon_{0}$ é a permissividade do vácuo, $\mathrm{E}_{\text {bias }}$ é o potencial externo de polarização, $\mathrm{E}_{\mathrm{FB}}$ é o potencial de banda plana e q é o valor de carga elementar. Esse equacionamento assume que (i) todos os níveis aceptores ou doadores do dopante estão ionizados; (ii) uniformemente distribuídos e imóveis; (iii) o nível de Fermi $\left(\mathrm{E}_{\mathrm{f}}\right)$ encontra-se a mais de $2 \mathrm{kT}(0,05 \mathrm{eV})$ de distância da banda mais próxima (semicondutor não-degenerado); e (iv) a intensidade de polarização não fez a SCL atingir o modelo de inversão. Essas considerações mostram a importância do modelo de esgotamento (Figura 6C) para a determinação da espessura da SCL, bem como para a determinação do $\mathrm{E}_{\mathrm{FB}}$. Nele, a quantidade de transportadores na interface do semicondutor é muito menor do que na interface do eletrólito e até do que os níveis intrínsecos. Desse modo, o potencial aplicado não afeta o decaimento de potencial na camada de Helmholtz. ${ }^{14}$ Para que isso aconteça, a concentração de transportadores de carga majoritários do semicondutor deve se equiparar à de íons do eletrólito, algo possível com a aplicação do potencial suficientemente abaixo do $\mathrm{E}_{\mathrm{FB}}$ para semicondutores n ou suficientemente acima para semicondutores p, para além dos limites do modelo de camada de acumulação (Figura 6B).

Ao aplicar $\mathrm{E}_{\text {bias }}<<\mathrm{E}_{\mathrm{FB}}$ ou $\mathrm{E}_{\text {bias }}>>\mathrm{E}_{\mathrm{FB}}$ para semicondutores tipo $\mathrm{n}$ e $\mathrm{p}$, respectivamente, os transportadores majoritários do material inundam a interface, elevando a concentração de transportadores de carga a nível comparável ao de metais. $\mathrm{O}_{\mathrm{f}}$ adentra a banda adjacente e, portanto, a interface adota caráter de um semicondutor degenerado (quase-condutor). Nessa condição, o arqueamento de bandas costuma ser desconhecido e o potencial aplicado passa a controlar também o potencial interfacial das bandas (intersecção com o eixo de energia e/ou potencial). ${ }^{14}$

A última consideração diz respeito à transição entre os modelos de esgotamento e inversão (Figura 6C e 6D). Como já explicado, ao se aplicar potencial acima do $\mathrm{E}_{\mathrm{FB}}$ a qualquer semicondutor $\mathrm{n}$, ou abaixo para semicondutores $\mathrm{p}$, inicialmente, drena-se os transportadores majoritários da interface permanecendo apenas os estados ionizados e imóveis do dopante (átomos substituídos na rede cristalina do material) com carga oposta. Nessa circunstância diz-se que o eletrodo se encontra em estado de bloqueio, pois não há concentração de transportadores suficiente para a condução de reações faradáicas 
interfaciais. Contudo, ao se elevar a amplitude do potencial aplicado (ainda mais positivo para $\mathrm{n}$ e mais negativo para $\mathrm{p}$ ), dois fenômenos diferentes podem ocorrer de acordo com a largura do Band Gap do material (Figura 9).
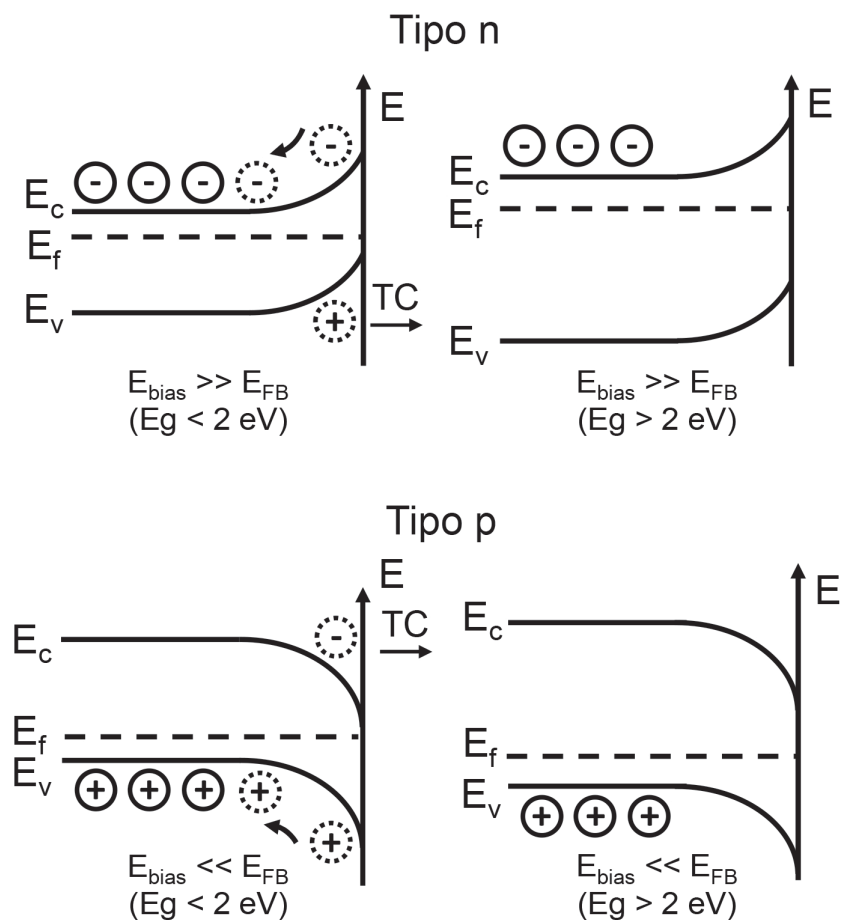

Figura 9. Modulação da space-charge layer pela aplicação de potencial de polarização reverso de amplitude além dos limites da camada de esgotamento, formando a camada de inversão para semicondutores com Band Gap abaixo de $2 \mathrm{eV}$ e a camada de esgotamento profundo para semicondutores com Band Gap acima de $2 \mathrm{eV}$. $E_{\text {bias: }}$ : potencial de polarização do substrato; $E_{F B}$ : potencial de banda plana; $E_{f}$ nível de Fermi; $E_{C}$ : potencial da borda da banda de condução; $E_{V}$ : potencial da borda da banda de valência; $E_{g}:$ Band Gap. TC: transferência de carga com o eletrólito interfacial. Adaptado da obra de FINKLEA ${ }^{14}$

Caso $\mathrm{Eg}<2 \mathrm{eV}$, além do estado de esgotamento, a elevação da amplitude faz o nível de Fermi se aproximar da banda inicialmente mais distante, que seria a banda de valência para um semicondutor $n$ e a banda de condução para o tipo p, de modo a desenvolver o modelo de camada de inversão (Figura 6D). Para o tipo $\mathrm{n}$ a transferência de carga (TC) ocorre com a BV através dos níveis intrínsecos de lacunas $\left(\mathrm{h}^{+}{ }_{\mathrm{BV}}\right)$, do mesmo modo que para o tipo $\mathrm{p}$ os processos faradáicos ocorrem pelos níveis intrínsecos de elétrons na $\mathrm{BC}\left(\mathrm{e}_{\mathrm{BC}}^{-}\right)$. Agora, se $\mathrm{Eg}>2 \mathrm{eV}$, tanto para semicondutores n ou p, o aumento da amplitude do potencial aplicado frente a $\mathrm{E}_{\mathrm{FB}}$ leva a space-charge layer a um estado de esgotamento profundo, já que o nível de transportadores intrínsecos é muito baixo e o eletrodo permanece no estado de bloqueio. ${ }^{14}$ As diferentes respostas de modulação da space-charge layer frente ao potencial de polarização encontram-se sumarizadas na Tabela 1 a seguir.

Cabe analisar as circunstâncias também sob o prisma da irradiação da interface com fótons contendo energia igual ou superior ao Band Gap do semicondutor. O material dopado apresenta uma grande disparidade entre a concentração dos dois tipos de transportadores, sendo que ao ser irradiado para a geração de um éxciton $\left(\mathrm{e}^{-}{ }_{\mathrm{BC}} / \mathrm{h}^{+}{ }_{\mathrm{BV}}\right)$, pouca diferença se observa na concentração do transportador de carga majoritário, mas um grande aumento se observa para o transportador minoritário. Assim, para que o foto-efeito possa ser mais pronunciado, os transportadores fotogerados devem dominar a resposta do eletrodo, o que é possível através da polarização do substrato para a geração de uma camada de esgotamento na interface irradiada (Figura 6C). ${ }^{14}$

Por exemplo, quando um semicondutor n é submetido (com o auxílio de um potenciostato) à polarização positiva suficientemente acima do $\mathrm{E}_{\mathrm{FB}}$, a corrente no escuro é muito baixa devido ao efeito de bloqueio do eletrodo. Ao ser irradiado com comprimentos de onda abaixo do Band Gap, observa-se valores consideravelmente altos de fotocorrente devido á geração e disponibilização de lacunas $\left(\mathrm{h}^{+}{ }_{\mathrm{BV}}-\right.$ transportador minoritário) na interface. Ao absorver luz e gerar o par $\mathrm{e}^{-}{ }_{\text {BC }} / h^{+}{ }_{\text {BV }}$ na camada de esgotamento (Figura 6C), o campo elétrico da região separa os transportadores de modo que os elétrons migram ao bulk do cristal e as lacunas para a superfície. Mesmo quando o éxciton é formado fora da região da camada de esgotamento, considera-se que os transportadores difundem até a região do campo elétrico e, a partir daí, são separados por migração. Esse é o principal mecanismo de separação espacial e supressão da recombinação em eletrodos de semicondutores extrínsecos. As lacunas na interface apresentam o poder oxidante relativo ao potencial da borda da banda de valência $\left(E_{B V}\right)$ e são capazes de oxidar quaisquer moléculas no estado reduzido com potencial formal inferior a ele no eletrólito, termodinamicamente falando. Para semicondutores com Band Gap largo, como é o caso do $\mathrm{TiO}_{2}$, as lacunas são capazes de oxidar a própria água, quando esse é o solvente do eletrólito. Os elétrons são conduzidos até o substrato condutor e seguem por um circuito externo até o eletrodo auxiliar (intermediados, p.ex., pelo conversor corrente/tensão e amplificador do potenciostato), provendo a carga transferida em processos de redução. ${ }^{14}$

Agora focando nos processos anódicos, acometendo um eletrodo de trabalho constituído de semicondutor $\mathrm{n}$ sobre leito condutor, polarizado a um potencial acima do potencial de banda plana $\left(\mathrm{E}_{\mathrm{bias}}>\mathrm{E}_{\mathrm{FB}}\right.$ : Esgotamento - Figura 6C) e sob um fluxo de fótons $\left(\mathrm{I}_{0}\right)$, os efeitos da fotoexcitação e dos processos de injeção de carga nas lacunas levam a um formato característico de voltamograma (Figura 10) que foi alvo de modelamento por um número elevado de autores. ${ }^{30-36}$

O formato do voltamograma depende dos seguintes fatores: a distribuição de energia dos fótons incidentes; o coeficiente de absorção do semicondutor; a distância de difusão para as lacunas e elétrons fotogerados até atingir a SCL; e a taxa de recombinação $\mathrm{e}^{-}{ }_{\mathrm{BC}}{ }^{\prime}$ $\mathrm{h}^{+}{ }_{\mathrm{BV}}$. A condição de análise mais simples se dá quando os fótons são absorvidos na própria camada de esgotamento, onde o campo elétrico permite condição de mínima recombinação entre os transportadores. Desconsiderando-se as limitações de transporte de massa da espécie

Tabela 1. Modelo de resposta da Space-Charge Layer ao potencial de polarização externo aplicado no substrato condutor usado como leito ao material semicondutor

\begin{tabular}{lccccc}
\hline Potencial/Tipo & & \multicolumn{3}{c}{ Modelo de Camada } & \\
\cline { 2 - 6 } & $\mathrm{E}_{\text {bias }}=\mathrm{E}_{\mathrm{FB}}$ & $\mathrm{E}_{\text {bias }}>\mathrm{E}_{\mathrm{FB}}$ & $\mathrm{E}_{\text {bias }}<\mathrm{E}_{\mathrm{FB}}$ & $\mathrm{E}_{\text {bias }}>>\mathrm{E}_{\mathrm{FB}}$ & $\mathrm{E}_{\mathrm{bias}}<<\mathrm{E}_{\mathrm{FB}}$ \\
\hline$n\left(\mathrm{E}_{\mathrm{g}}<2 \mathrm{eV}\right)$ & Bandas Planas & Esgotamento & Acumulação & Inversão & Degeneração \\
$p\left(\mathrm{E}_{\mathrm{g}}<2 \mathrm{eV}\right)$ & Bandas Planas & Acumulação & Esgotamento & Degeneração & Inversão \\
$n\left(\mathrm{E}_{\mathrm{g}}>2 \mathrm{eV}\right)$ & Bandas Planas & Esgotamento & Acumulação & Esgotamento Profundo & Degeneração \\
$p\left(\mathrm{E}_{\mathrm{g}}>2 \mathrm{eV}\right)$ & Bandas Planas & Acumulação & Esgotamento & Degeneração & Esgotamento Profundo \\
\hline
\end{tabular}




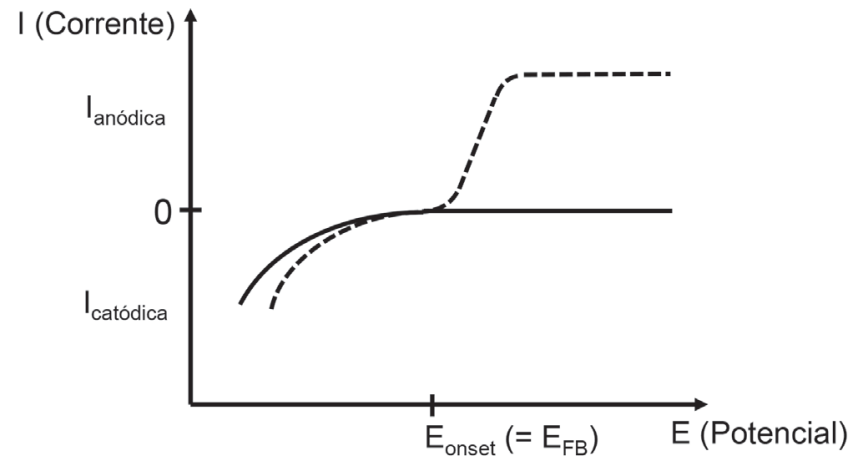

Figura 10. Voltamogramas apresentando a dependência da corrente no escuro (-) e da fotocorrente (---) com a aplicação de potencial de polarização crescente em eletrodo de semicondutor extrínseco $n$. $E_{\text {onser }}$ : potencial no qual se inicia a medida de corrente anódica; $E_{F B}$ : potencial de banda plana. Baseado em figura da obra de Finklea ${ }^{14}$

doadora de elétrons no eletrólito, a eficiência de fotoconversão de fótons em elétrons compondo a fotocorrente no filme se aproxima da unidade. A partir do momento em que a espessura da camada de esgotamento excede a penetrabilidade da radiação incidente no filme, a eficiência quântica da fotocorrente passa a não mais depender do potencial, por isso nota-se o nivelamento da fotocorrente (Figura 10). Mas, à medida que o potencial se aproxima do $\mathrm{E}_{\mathrm{FB}}$, a espessura da camada de esgotamento diminui e limita a ação de supressão de recombinação do campo elétrico, levando ao encontro dos valores de fotocorrente e corrente no escuro. Em potenciais abaixo do $\mathrm{E}_{\mathrm{FB}}, \mathrm{O}$ eletrodo inicia o desenvolvimento de uma camada de acumulação e sai do estado de bloqueio, apresentando corrente pequena, pouco acima da corrente catódica no escuro. Geralmente são valores baixos, uma vez que elétrons fotogerados pouco alteram a concentração de elétrons superficiais que são fortemente controlados pelo nível de dopagem. ${ }^{14}$

Como anteriormente mencionado, muitos modelamentos foram criados para o transporte de carga sob o estímulo das condições descritas. O modelo mais simples e útil (Eq. 12) foi derivado assumindo-se a inexistência de recombinação na space-charge layer, de tal modo que toda lacuna gerada dentro ou difundida para a camada de esgotamento gera fotocorrente e que a fotocorrente é somente governada pelo fluxo de lacunas para interface, desprezando-se limitações cinéticas ou por transporte de solutos redutores.

$$
J_{p}=q I_{0}\left[1-e^{\frac{-\alpha W}{1+\alpha L}}\right]
$$

em que $\mathrm{J}_{\mathrm{p}}$ é a densidade de fotocorrente; $\mathrm{I}_{0}$ é fluxo de fótons incidente; W é a espessura da camada de esgotamento; L é o comprimento de difusão para os transportadores minoritários fotogerados; q é o valor de carga elementar; e $\alpha$ é o coeficiente de absorção do material. $\mathrm{O}$ rearranjo da Eq. 10 com a Eq. 9 e a Eq. 6 leva a um modelo capaz de descrever completamente a camada de esgotamento em termos da resposta de fotocorrente-potencial e fotocorrente-comprimento de onda. Através da manipulação desenvolvida por Fornarini et al., ${ }^{37}$ é possível gerar relações lineares simples que levam à determinação da energia do Band Gap e do tipo de transição (direto ou indireto) do semicondutor. Ao utilizar comprimentos de onda em que não se observa uma forte absorção por parte do semicondutor, p. ex. próximo à Eg, a luz é capaz de penetrar além da camada de esgotamento e, com $\alpha \mathrm{W}$ e $\alpha \mathrm{L}<<1$ a Eq. 10 pode ser transformada na Eq. 11.

$$
\frac{J_{p} h v}{q I_{0}}=(L+W) A(h v-E g)^{\frac{m}{2}}
$$

em que $\mathrm{J}_{\mathrm{p}}$ é a densidade de fotocorrente; h é a constante de Planck; $v$ é a frequência da radiação incidente; q é o valor de carga fundamental; $\mathrm{I}_{0}$ é o fluxo incidente de fótons, $\mathrm{L}$ é o comprimento de difusão para os transportadores minoritários fotogerados; W é a espessura da camada de esgotamento; A é uma constante; Eg é a energia de Band Gap; e m é o fator de transição do Band Gap (direto ou indireto). Ao plotar um gráfico de $\log \left[\mathrm{J}_{\mathrm{p}} \mathrm{h} v / \mathrm{q} \mathrm{I}_{0}\right]$ vs. $\log (\mathrm{h} v-\mathrm{Eg})$ sob potencial de polarização constante, obtêm-se uma função de dependência linear com coeficiente angular igual a $1 / 2(\mathrm{~m}=1$ para Band Gap direto $)$ ou 2 ( $\mathrm{m}=4$ para Band Gap indireto). Em outra abordagem, ao plotar $\left[\left(\mathrm{J}_{\mathrm{p}} \mathrm{h} v / \mathrm{qI}_{0}\right)\right]^{2 / \mathrm{m}} v s$. hv obtêm-se o valor de Eg do semicondutor como intersecção do eixo das ordenadas (coeficiente linear da função).

$\mathrm{Na}$ abordagem apresentada até aqui, pode-se perceber a importância dada aos modelos de space-charge layer para o desenvolvimento da ciência de semicondutores e, mais especificamente, a versatilidade dos ensaios fotoeletroquímicos na sua caracterização a ponto de até propriedades fundamentais puramente ópticas poderem ser determinadas por eles. Com o desenvolvimento da ciência de nanomateriais, muitos desses conceitos fortemente sedimentados ao final da década de 1980 foram revistos vez que não se aplicavam aos filmes compostos por nanopartículas. Dentre esses conceitos pode-se apontar a refutação inclusive do desenvolvimento de uma space-charge layer, ${ }^{38}$ como será discutido no tópico a seguir.

\section{FOTOEXCITAÇÃO, SEPARAÇÃO E TRANSPORTE DE CARGA EM FILMES NANOPARTICULADOS E SUA COMPARAÇÃO COM ELETRODOS MONOCRISTALINOS DOPADOS}

Nanopartículas muito pequenas podem ser vistas como moléculas gigantes ou clusters, contendo de algumas dezenas a milhares de átomos e orbitais atômicos (Build up Approach). Ou ainda, como pequenos cristais separados do bulk (Top-Down Approach). ${ }^{17} \mathrm{~A}$ classe de nanopartículas tendendo a diâmetros da ordem de algumas unidades de nanômetro (<6 nm) é chamada de Quantum Dots. ${ }^{17,39,40}$ Sua estrutura eletrônica pode ser caracterizada pela elevada densidade de estados no centro da banda, e pela formação de níveis discretos nas bordas (Figura 11).

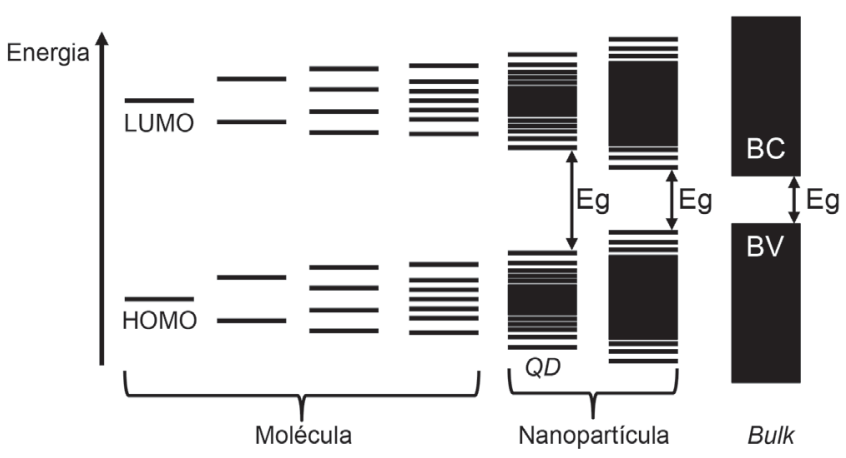

Figura 11. Organização dos níveis de energia ou orbitais moleculares partindo (da direita à esquerda) de uma molécula diatômica ao bulk. $E_{g}$ : Band Gap; BC: banda de condução; BV: banda de valência; LUMO: lowest unoccupied molecular orbital; HOMO: highest occupied molecular orbital; QD: quantum dots. Adaptado da tese de Groeneveld ${ }^{20}$

Essas evidências observadas na estruturação dos níveis ocorrem de acordo com o Efeito de Confinamento Quântico. .77,39,40 Além de representar a quebra de quasi-continuidade de níveis de energia da teoria de banda em bulks, demonstra o aumento da energia de Band Gap com a redução dos diâmetros de partícula através da diferença de energia entre os orbitais HOMO e LUMO (Figura 11). Os limites 
de dimensão para o regime de confinamento, classificado em forte ou fraco, são ditados por um parâmetro criado em analogia ao raio atômico de Bohr do Hidrogênio: o raio de Bohr do éxciton $\left(\mathrm{r}_{\mathrm{B}}\right) \cdot{ }^{17,38}$

$$
r_{B}=\frac{h^{2} \varepsilon_{0} \varepsilon}{e^{2} \pi m_{e f}}
$$

em que $\mathrm{r}_{\mathrm{B}}$ é o raio de Bohr do éxciton; h é a constante de Planck normalizada; $\varepsilon_{0}$ é a permissividade do vácuo; $\varepsilon$ é a constante dielétrica da partícula; "e" é o valor de carga elementar; e $\mathrm{m}_{\mathrm{ef}}$ é a massa efetiva. $\mathrm{O}$ $\mathrm{r}_{\mathrm{B}}$ determina a distância mais provável entre o elétron e a lacuna em um éxciton, de modo que para raios de partículas inferiores ou iguais a $r_{B}$, observa-se o regime de confinamento forte, no qual a energia cinética de ambos os transportadores supera em muito a sua interação coulombiana, podendo, portanto, cada um ser tratado independentemente do ponto de vista energético. A soma de suas energias relativas leva à energia de confinamento que, somada à energia de Band Gap original do material, induz ao novo valor referente a comprimentos de onda de excitação mais baixos. Quando o raio da nanopartícula supera o $\mathrm{r}_{\mathrm{B}}$ até o limite do seu dobro ou triplo, o regime de confinamento é classificado como fraco e, apesar de serem observadas mudanças nos níveis de energia, essas são muito mais moderadas do que no regime de confinamento forte. ${ }^{17}$

Particularmente útil é a relação que $\mathrm{r}_{\mathrm{B}}$ apresenta com o Band Gap dos materiais: quanto maiores os valores de $\mathrm{Eg}$, menores os de $\mathrm{r}_{\mathrm{B}}$. Essa relação mostra que materiais diferentes experimentam o regime de confinamento em tamanhos distintos, como por exemplo: para o $\mathrm{PbSe}, \mathrm{Eg}=0,26 \mathrm{eV}(4769 \mathrm{~nm})$ e $\mathrm{r}_{\mathrm{B}}=46 \mathrm{~nm}$; para o $\mathrm{ZnS}, \mathrm{Eg}=3,7 \mathrm{eV}$ $(335 \mathrm{~nm})$ e $\mathrm{r}_{\mathrm{B}}=1,5 \mathrm{~nm}$. Quanto mais isolante for o material (Eg elevado), maior a localização do éxciton ( $\mathrm{m}_{\mathrm{ef}}$ maiores) e menores os tamanhos de partícula requeridos para que o material sofra os fatores de confinamento. ${ }^{17}$

Afora as diferenças nas propriedades ópticas causadas pelo confinamento quântico, a redução dos tamanhos de partícula, mesmo a diâmetros de dezenas de nm, ainda apresenta outras particularidades importantes. Ao dividir finamente um material semicondutor dopado, limita-se fortemente a quantidade de sítios de dopante ionizados presentes em cada nanopartícula formada, aproximando-as do estado de semicondução intrínseca. ${ }^{38,41} \mathrm{Em}$ alguns casos, quando aplicada concentração de dopante análoga ao estado monocristalino, a maioria das partículas encontra-se sem nenhum átomo dopante, enquanto a minoria restante tem de um a dois átomos. ${ }^{41} \mathrm{O}$ esgotamento de transportadores acaba sendo ainda mais pronunciado pelo fato de que filmes nanoparticulados são penetrados pelo eletrólito interfacial, de modo que para atingir o equilíbrio dos níveis de Fermi entre as fases $\left(\mathrm{E}_{\mathrm{f}}=\mathrm{E}^{\prime}\right)$ observa-se a transferência dos transportadores das partículas aos aceptores no eletrólito, aprofundando ainda mais a depleção. ${ }^{38,41}$

A distribuição de potencial em semicondutores esféricos foi derivada a partir de uma equação linearizada de Poisson-Boltzmann e, a partir dela, determinou-se o decaimento de potencial observado em nanopartículas de acordo com o seu raio (Eq. 13). ${ }^{38}$

$$
\Delta \Phi_{0}=\frac{k T}{6 e}\left(\frac{r_{0}}{L_{D}}\right)^{2}
$$

em que $\Delta \Phi_{0}$ é a diferença de potencial entre o centro e a borda da partícula; $\mathrm{k}$ é a constante de Boltzmann; $\mathrm{T}$ é a temperatura absoluta em Kelvin; $\mathrm{r}_{0}$ é o raio da partícula; e $\mathrm{L}_{\mathrm{D}}$ é o comprimento de Debye $\left(\mathrm{L}_{\mathrm{D}}\right.$ decai proporcionalmente com a raiz quadrada da concentração de dopante). Como o raio de nanopartículas é pequeno, a dopagem deve atingir valores altos para que o comprimento de Debye decaia suficientemente e aumente a diferença de potencial entre as bordas e o núcleo da partícula, havendo assim o desenvolvimento de um campo elétrico com efeito prático. Com o esgotamento de transportadores majoritários protagonizado principalmente pela percolação de eletrólito no filme nanoparticulado, ${ }^{41}$ conclui-se que a principal forma de transporte de carga através das partículas é a difusão. Uma regra prática mostra que a diferença de potencial entre as bordas e o núcleo das partículas deve atingir o valor de $50 \mathrm{mV}$ para que o transporte seja realizado predominantemente por migração elétrica ao invés de difusão. ${ }^{38}$ Valores abaixo disso denotam um campo desprezível, podendo-se igualmente desprezar a formação de space-charge layer (Figura 12). Sugere-se, nessa circunstância, que o eletrodo permanece com bandas planas e que qualquer variação de potencial deve decair na camada de Helmholtz ([eletrólito] > 0,1 $\mathrm{mol} \mathrm{L}^{-1}$ ), representando uma mudança na posição da borda das bandas.

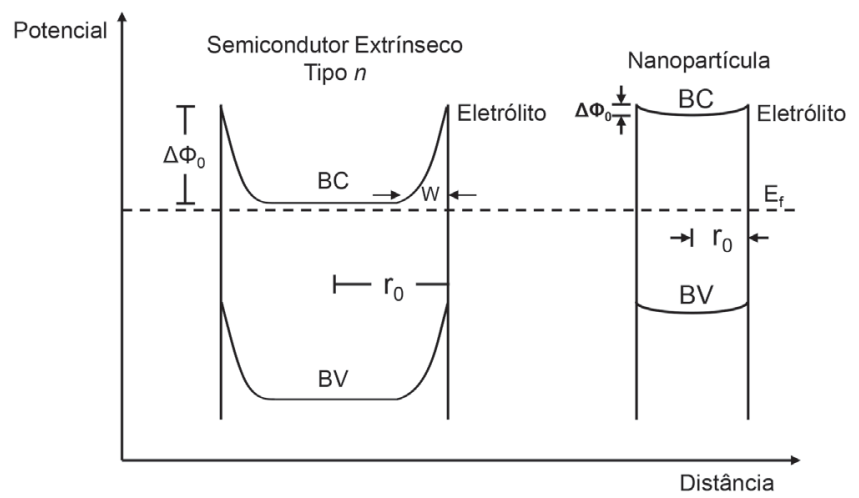

Figura 12. Formação da space-charge layer em partículas grandes de semicondutores extrínsecos do tipo n e em nanopartículas de semicondutores em equilíbrio com uma espécie redox do eletrólito com potencial formal igual ao nível de Fermi $\left(E_{f}\right)$. A nanopartícula encontra-se praticamente esgotada de transportadores, com o nível de Fermi localizado aproximadamente no centro do Band Gap e arqueamento de bandas negligenciável. BC: banda de condução; $B V$ : banda de valência; $r_{0}$ : raio da partícula; W: espessura da space-charge layer medida no modo de camada de esgotamento; $\Delta \Phi_{0}$ : decaimento de potencial na space-charge layer relativo ao arqueamento de bandas. Adaptado do trabalho de revisão de Hagfeldt e Grätzel ${ }^{38}$

Em filmes nanoparticulados, o esgotamento de transportadores causado tanto pelo efeito de redução de diâmetro como pela penetração de eletrólito faz com que os transportadores gerados por fotoexcitação possam se tornar majoritários e, assim, a condutividade do material passe a ser controlada pela etapa limitante do processo de injeção de carga interfacial..$^{42,43}$ Ao irradiar um filme nanoparticulado com fótons com energia superior ao Band Gap, há igualmente a formação de elétrons excitados na banda de condução $\left(\mathrm{e}_{\mathrm{BC}}{ }^{-}\right)$e lacunas na banda de valência $\left(\mathrm{h}_{\mathrm{BV}}^{+}\right)$. Tanto a acepção do elétron como a captura da lacuna por espécies no eletrólito podem ser reações plausíveis, de modo que o tipo de reação predominantemente mais rápida leva a um novo tipo de classificação do material.

Semicondutores nanoparticulados n são aqueles em que a cinética de reação da lacuna $\left(\mathrm{h}_{\mathrm{BV}}^{+}\right)$com o eletrólito é mais rápida e os elétrons provenientes tanto da excitação como da transferência de carga são chamados de transportadores de vida longa. ${ }^{42}$ Eles levam a um carregamento negativo do filme e, ao se aplicar potenciais positivos frente ao potencial de corrente nula $\mathrm{E}_{\text {onset }}\left(\approx \mathrm{E}_{\mathrm{FB}}\right)$, são os transportadores que apresentam mobilidade e podem ser medidos sob forma de uma corrente anódica durante registros voltamétricos. Semicondutores nanoparticulados p são aqueles em que o elétron reage mais rápido com um componente do eletrólito, de modo que as lacunas passam a ser os transportadores de vida longa que conferem um carregamento positivo ao filme e são transportados através dele pela aplicação de potenciais mais negativos frente ao $\mathrm{E}_{\text {onset }}$, sendo medida uma corrente 
catódica durante registros voltamétricos. ${ }^{42}$

No início dos estudos de fotoanodos com semicondutores nanoparticulados, o transporte de carga através desses filmes era visto como algo efetivamente pouco provável, uma vez que não se observava o campo elétrico provindo do arqueamento de bandas da space-charge layer para a separação espacial dos transportadores de carga oposta, que inicialmente deveriam recombinar em massa. Além disso, o transporte de carga inter-partícula também parecia algo complicado, uma vez que o transportador deveria vencer uma barreira coulombiana de até $50 \mathrm{meV}$, dependendo do contato entre os cristalitos, ${ }^{41}$ com resistividades da ordem de $10^{9} \Omega \mathrm{cm} .{ }^{44}$ Afora isso, o efeito favorável de ganho de área pela penetração do eletrólito, que é estimado em 1000 vezes para um filme com algumas unidades de $\mu \mathrm{m}$ de espessura ${ }^{41}$ parecia bastante promissor, principalmente para o desenvolvimento de células solares fotosensibilizadas por corante.

A resposta a esses problemas veio a partir da própria natureza dos processos, que mostraram certa capacidade de transporte de carga nos filmes nanoparticulados. Por exemplo, em semicondutores nanoparticulados $\mathrm{n}$ a lacuna $\left(\mathrm{h}^{+}{ }_{\mathrm{BV}}\right)$ é um transportador que apresenta tempo de vida curto. ${ }^{3}$ Em outras palavras, ou ela é gerada e reage com um doador em solução ou ela recombina com um elétron fotoexcitado. ${ }^{42}$ O tempo de vida do éxciton é aumentado pelo processo de trapping, ampliando o período para a incidência de reações interfaciais antes da recombinação. ${ }^{25}$ Após a injeção de um elétron na lacuna, o elétron na BC (ou no trap) é transportado para o eletrodo polarizado positivamente. Caso o filme seja composto por Quantum Dots, a função de onda dos transportadores é espalhada por toda a extensão espacial da partícula, de modo que os mesmos não precisam se difundir do ponto de onde foram gerados para as bordas. Assim, os elétrons se deslocam ao condutor sem encontrar pela frente lacunas para se recombinar. Há chances de sequestro desse elétron por reações com aceptores eletrônicos presentes no eletrólito durante a etapa de transferência inter-partícula, já que o eletrólito circunda a maior parte das partículas componentes do filme poroso. O potencial redox disponível para tanto será o da borda da banda de condução do material ou do potencial relativo do elétron no estado de relaxamento do trap, sendo que as perdas de fotocorrente dependem também da cinética de captura do elétron pelo suposto aceptor.

Quanto à improvável transferência de transportadores entre diferentes partículas, a presença do eletrólito entre elas facilita este processo. O desenvolvimento da carga negativa das partículas n pela presença de elétrons acumulados no filme leva ao pareamento de cátions e orientação do dipolo das moléculas do solvente (se polarizável, como $\mathrm{H}_{2} \mathrm{O}$ ), o que reduz a barreira coulombiana para valores termicamente acessíveis à temperatura ambiente, como reportado por Brus. ${ }^{45}$ Todavia, a eficiência do transporte de carga em filmes nanoparticulados é bastante prejudicada frente aos eletrodos monocristalinos.

Mesmo em semicondutores intrínsecos, no estado monocristalino, a aplicação de potencial leva ao transporte vetorial dos transportadores, o que não ocorre em filmes nanoparticulados devido ao seu caráter descontínuo. Considera-se que o transporte de carga se dá inteiramente pela difusão causada pelo gradiente de concentrações do transportador ao longo do filme nanoparticulado. ${ }^{38}$ Essas características se refletem nos respectivos coeficientes de difusão do elétron $\left(D_{0}\right)$ em cada tipo de estrutura. ${ }^{46}$ Por exemplo, em monocristais $D_{0}$ está próximo a valores de $4,010^{-1} \mathrm{~cm}^{2} \mathrm{~s}^{-1}$, enquanto que para filmes nanoparticulados é de cerca de $1,410^{-3} \mathrm{~cm}^{2} \mathrm{~s}^{-1}$, ou seja, quase 300 vezes menor.

Em filmes nanoparticulados, durante o transporte de carga, o transportador pode ser eliminado principalmente pela recombinação (fator comum aos eletrodos monocristalinos) e pela sua captura por aceptores na etapa de transferência inter-partícula (fator próprio). Todavia, em monocristais dopados a existência da $S C L$ permite o decaimento do potencial em sua extensão (no mínimo de $50 \mathrm{mV})^{38} \mathrm{de}$ modo a formar um campo elétrico que separa espacialmente lacunas de elétrons para evitar a recombinação na interface. Um dos transportadores é levado à interface para se transferir a uma espécie eletroativa, gerando o aumento da concentração do transportador oposto, o qual migra sob efeito do campo elétrico em direção ao bulk do semicondutor. Nessa região há alta concentração de transportadores da sua própria espécie e ínfima concentração do transportador oposto, sendo, portanto, muito baixa a probabilidade de recombinação. A existência do campo elétrico na interface, nesse caso, suprime fortemente a recombinação na profundidade de penetração da radiação incidente, e é essa a principal função da dopagem de semicondutores nas células fotoeletroquímicas condutivas. Utiliza-se o transportador fotogerado de carga oposta à dopagem para a reação química com as espécies no eletrólito.

De outro lado existem os filmes nanoparticulados que não suportam a formação de $S C L$ e assim não apresentam campo elétrico para separação de cargas. A melhor condição encontrada para supressão de recombinação é em Quantum Dots, em que o transportador reativo depende apenas da cinética da reação de transferência de carga para ser extinto e o transportador de vida longa deve percorrer um filme praticamente isento do transportador oposto, sendo realmente baixa a possibilidade de recombinação. ${ }^{42}$ Nesse caso a maior fonte de perdas de transportadores no percurso ao eletrodo polarizado é a captura por espécies durante a transferência inter-partícula. ${ }^{42} \mathrm{Já}$ em nanopartículas maiores $\left(r>>r_{B}\right)$, ambos os transportadores difundem dentro das partículas e a chance de recombinação é muito maior durante o transporte ao condutor. Assim, desponta a importância de utilizar filmes nanoparticulados finos, principalmente quando se trabalha acima do limite de tamanho dos Quantum Dots e enseja-se alta eficiência de coleta. ${ }^{47}$ Apesar do menor coeficiente de absorção $(\alpha)$ e consequentemente menor extensão de reação interfacial, ao reduzir o percurso do transportador diminui-se drasticamente a probabilidade de recombinações, sequestro por espécies eletroativas na transferência inter-partícula e inclusive a resistência ôhmica do filme, diminuindo o potencial de polarização mínimo para otimização do fator de coleta.

E, por fim, cabe apreciar o papel da aplicação de potencial de polarização em substratos condutores modificados com filmes de materiais nanoparticulados. Não se observam muitos trabalhos dispostos a essa discussão e alguns autore ${ }^{48}$ se limitam a dizer que a aplicação do potencial não causa a supressão da recombinação e exaltam a necessidade da dopagem. Outros, como Jiang et al. ${ }^{49}$ mostram que a aplicação de potencial, dependendo do valor, possibilita coletar os elétrons de modo a evitar seu acúmulo na interface e, indiretamente, reduzir a taxa de recombinação. Esse último grupo de autores discute uma possível inconsistência no transporte puramente por difusão, defendendo a formação de um campo elétrico e o transporte de carga com pouca dependência, em termos de mobilidade eletrônica, dos efeitos de blindagem dos cátions (e solvente) interfaciais do eletrólito.

O que se confirma na prática é que o comportamento do nanomaterial na forma de um filme nanoporoso se aproxima de um isolante, com uma faixa linear em regiões logo após o potencial de corrente nula (acima ou abaixo de $\mathrm{E}_{\text {onset }}$ dependendo se semicondutor tipo $\mathrm{n}$ ou p) seguindo até o nivelamento da fotocorrente em um valor constante, ou seja, não mais dependente do aumento do potencial aplicado: a corrente de saturação. De fato, a fotocorrente depende em larga faixa do potencial aplicado. Entretanto, ele não regula a cinética de reações interfaciais. ${ }^{43}$ Os transportadores são fotogerados pela luz e reagem com espécies na interface em decorrência do potencial conferido pela sua respectiva borda de banda, ${ }^{27}$ sendo os transportadores de vida longa drenados ao substrato condutor. Caso um potencial abaixo do mínimo necessário para atingir a fotocorrente de saturação seja aplicado, isso não significa que a reação interfacial possui velocidade 
mais lenta, mas sim que o potencial aplicado não é suficiente para coletar todos os transportadores acumulados para um mesmo tempo de irradiação.

A reação de fotooxidação interfacial depende apenas do fluxo radiante da fonte de excitação e da concentração de doadores (para reagir com lacunas) ou aceptores (para reagir com elétrons) na interface. ${ }^{43}$ Assim, o potencial de polarização tem a função de drenar os transportadores acumulados, sem um compromisso com a cinética das fotorreações ou mesmo com o complemento do potencial termodinâmico para a efetivação delas. Caso a banda do respectivo transportador não tenha o potencial necessário para reagir com a espécie interfacial, o potencial aplicado não complementa a demanda energética, não sendo o processo viável.

Portanto, conclui-se a grande contribuição que eletrodos nanoparticulados podem trazer à eletroquímica de semicondutores: a possibilidade de construir dispositivos que visem o estudo cinético da etapa limitante das reações dos transportadores fotogerados com as espécies eletroativas de interesse nos diferentes tipos de sítio de reação, já que o eletrodo polarizado funciona como uma sonda das reações interfaciais. ${ }^{49}$ Em alguns tipos de sítio a reação pode eventualmente ser controlada por transporte, de modo a poder-se estudar o decaimento da concentração do soluto de acordo com seu coeficiente de difusão em solução. ${ }^{50,51}$ Em outros tipos, o decaimento da concentração do soluto pode ser dependente da cinética de formação dos complexos superficiais. ${ }^{50,51}$ Isso é particularmente útil no estudo da degradação de poluentes orgânicos solubilizados visando, por exemplo, novos métodos de tratamento de águas baseado nesse processo oxidativo avançado. ${ }^{52}$

\section{APLICAÇÕES DA FOTOELETROCATÁLISE}

Na literatura internacional há uma vasta gama de artigos revendo aplicações do processo fotoeletrocatalítico para as mais diversas áreas e finalidades, além de apresentar perspectivas e novos desafios. Bessegatto et $a l .{ }^{52}$ revisaram as aplicações das estruturas com diferentes morfologias nanométricas do $\mathrm{TiO}_{2}$ para (i) a degradação de poluentes orgânicos através de reações de transferência de carga de suas lacunas $\left(\mathrm{h}^{+}\right)$com elevado poder oxidante, diretamente com o soluto orgânico ou via reação indireta com a formação de radicais hidroxila (HO'); (ii) redução de contaminantes inorgânicos via transferência de carga de seus elétrons com a espécie em solução; (iii) inativação de microorganismos patógenos pela reação de lacunas/ radicais hidroxila com os compostos constituintes de sua membrana plasmática, organelas e até seu DNA; (iv) produção de hidrogênio através da decomposição da água, pela simultânea redução de algumas moléculas com os elétrons fotoexcitados $\left(\mathrm{H}_{2} \mathrm{O} / \mathrm{H}_{2}\right)$ e oxidação de outras com as lacunas $\left(\mathrm{H}_{2} \mathrm{O} / \mathrm{O}_{2}\right)$ em fotopotencial de circuito aberto. Outro aspecto interessante revisado pelos autores é a redução do gás carbônico a espécies de forte valor comercial agregado, como hidrocarbonetos puros ou oxigenados (p. ex. $\mathrm{CO}_{2} / \mathrm{CH}_{3} \mathrm{OH}$ ), com elevada eficiência de conversão. Utilizando um composto de sacrifício para reação com lacunas ou aplicando potencial de polarização abaixo do potencial de bandas planas em semicondutores $\mathrm{p}$, pode-se elevar a taxa de conversão da fotorreação, atingindo-se valores bastante interessantes em algumas horas (>95\%) para eletrodos de materiais de baixo custo, como o $\mathrm{CuO} / \mathrm{Cu}$. Daghrir et al. ${ }^{53}$ revisaram as aplicações ambientais dos processos fotoeletrocatalíticos envolvendo eletrodos de $\mathrm{TiO}_{2}$ de um ponto de vista pragmático, através do estudo dos reatores e os fatores que afetam sua eficiência para a degradação de diversos poluentes orgânicos e inativação de microorganismos (E. coli), como a fonte de radiação UV implementada, aplicação de potencial externo, intensidade de luz, temperatura, e os fatores atrelados à amostra em tratamento, como o pH, concentração de oxigênio dissolvido e concentração de eletrólitos. Zhang et al. ${ }^{54}$ revisaram muitos dos mesmos parâmetros voltados para a degradação de poluentes orgânicos recalcitrantes (p. ex. Fenol) com eletrodos de filme de $\mathrm{TiO}_{2}$, mas também a influência da estrutura cristalina do filme de semicondutor, da sua espessura, do material usado como substrato leito, da dopagem do $\mathrm{TiO}_{2}$ com metais e não-metais, além de propor uma revisão dos mecanismos e a cinética para a degradação fotoeletrocatalítica de poluentes orgânicos. Egerton, ${ }^{55}$ comparando a eficiência do processo fotoeletrocatalítico frente ao fotocatalítico em suspensão para quatro reações diferentes de oxidação do nitrofenol, oxalato, inativação da bactéria $E$. coli e degradação do corante reativo laranja, chegou a conclusão de que, ao aplicar um pequeno potencial acima do potencial de bandas planas, há um aumento da taxa de oxidação dos poluentes; todavia não o suficiente para tornar o processo tecnologicamente viável. $\mathrm{O}$ autor desenvolveu sua discussão de acordo com as possíveis limitações impostas pelo design do reator frente àquelas previstas pelo tipo de material semicondutor e, em última análise, creditou ao material o baixo desempenho. Ao revisar o uso de nanotubos de $\mathrm{TiO}_{2}$, igualmente chegou à conclusão de que sua performance também não atende à demanda tecnológica de custo. Certamente, o caráter ôhmico de filmes nanoparticulados e a inaplicabilidade da separação de cargas por desenvolvimento de camada de esgotamento da space-charge layer discutidos nesta revisão são capazes de explicar parte dos resultados observados pelo autor. Zhang et al. ${ }^{56}$ resumiram em seu artigo de revisão o desenvolvimento de materiais fotocatalisadores aplicáveis no tratamento de remediação ambiental e/ou em rotas de síntese. O trabalho foca nos diferentes materiais testados, como o $\mathrm{TiO}_{2}, \mathrm{ZnO}, \mathrm{SnO}_{2}, \mathrm{WO}_{3}, \mathrm{Fe}_{2} \mathrm{O}_{3}$ e CdS, e suas implicações no uso prático em fotocatálise, como a estabilidade química e fotoquímica, a modificação físico-química dos materiais para o aumento das velocidades de reação e rendimento, a extensão da sensibilidade dos materiais para janela dentro do espectro visível e o desenvolvimento de semicondutores de óxidos mistos com valores de Band Gap deliberadamente moduláveis. Os autores mostram que tanto cálculos teóricos como os resultados experimentais obtidos são convincentes em provar que os materiais desenvolvidos até então são fotocatalisadores altamente eficientes com significância para profundas mudanças no campo ambiental e econômico, prontos para servir de base, juntamente ao conhecimento gerado, para o desenvolvimento de fotocatalisadores de alta eficiência para fotoconversão solar. Karanasios et al..$^{57}$ revisou o uso da oxidação fotoeletrocatalítica como um método oxidativo avançado para a degradação de poluentes, dando ênfase na aplicabilidade sob iluminação na região do visível. Deste modo, os materiais utilizados como fotoanôdos na região do visível foram abordados, podendo ser classificados em semicondutores monocomponente, bi-componente ou materiais de $\mathrm{TiO}_{2}$ modificados, incluindo a dopagem com ametais, como C-, N- e S-, e a nanodecoração com metais, como Pt, Au e Ag. Os autores concluem que o processo fotoeletrocatalítico é um método eficiente para aumentar o desempenho da fotocatálise convencional para o caso de semicondutores imobilizados em substratos, sendo viável para tratamentos de água em pequena escala com reatores modulares e a purificação de ar. Eles acreditam que o processo tem futuro promissor, principalmente por acoplar o tratamento de águas com a geração de hidrogênio ou energia elétrica em fotocélulas combustível. Dentre os materiais sensíveis a luz solar, os materiais de $\mathrm{TiO}_{2}$ dopados com $-\mathrm{N}$ ou $-\mathrm{C}$ ou ainda nanodecorados com $\mathrm{Ag}$ ou Au são apontados como os mais promissores. Lianos ${ }^{58}$ recentemente revisou os aspectos fundamentais de células fotoeletrocatalíticas desenvolvidas para a produção de eletricidade ou hidrogênio, a partir da oxidação de um agente de sacrifício orgânico ou inorgânico e a redução da água, de prótons ou mesmo de oxigênio. Os aspectos principais de células fotoeletrocatalíticas foram revisados, como 
fotoânodos, fotocátodos, contra-eletrodos, os eletrólitos e os designs incluindo células em tandem e combinação de eletrodos. Os materiais para a construção de todos os componentes e as respectivas eficiências obtidas foram discutidos, chegando-se à conclusão de que poucos trabalhos efetivamente estudam materiais de considerável absorção do espectro solar, como $\mathrm{WO}_{3}, \mathrm{BiVO}_{4}$ ou $\mathrm{Fe}_{2} \mathrm{O}_{3}$, em fotoânodos de fotocélulas combustível. Sua eficiência depende da capacidade dos fotoânodos em oxidar os combustíveis, bem como dos processos de redução no contra-eletrodo, como a redução do oxigênio. Parte deste conhecimento pode ser adquirido dos estudos de célula combustível, levando em conta o desenvolvimento de materiais eletrocatalisadores da redução de oxigênio sem Pt ou outros metais nobres, o que prejudica a relação de custos dos projetos de célula. Ou seja, pouca atenção é dada ao material constituindo o contra-eletrodo, já que elevada complexidade é encontrada nos processos envolvendo o fotoeletrodo de trabalho, e isso certamente prejudica o desenvolvimento dos protótipos de fotocélulas. Afora esses aspectos, o autor conclui que as células fotoeletrocatalíticas alcançaram maturidade tecnológica, sendo importante confrontar os tradicionais problemas de ampliação de escala (scale-up). As células em tandem ainda constituem uma curiosidade científica longe de viabilidade prática devido ao design e os custos dos materiais, sendo ainda preferível o acoplamento de células fotoeletrocatalíticas com células fotovoltaicas comerciais.

\section{CONSIDERAÇÕES FINAIS}

No limitado número de páginas de um artigo de revisão, seria impossível tratar em profundidade de todo o corpo de conhecimento teórico e experimental em que se apoia a compreensão atual dos fenômenos envolvidos nos processos de fotoeletrocatálise em semicondutores e sua aplicação prática, tampouco de analisar criticamente a vasta e crescente literatura sobre o assunto. Acredita-se ter sido possível, no entanto, selecionar e introduzir em linguagem acessível aos químicos interessados a ingressar nesse ativíssimo campo de pesquisa os aspectos essenciais da ciência de semicondutores e do desenvolvimento dos modelos vigentes para explicação do papel da eletrocatálise aos fenômenos fotocatalíticos de semicondutores, inclusive nanoparticulados e imobilizados em substratos condutores. A compreensão dos diversos mecanismos envolvidos permite melhor controle dos processos fotocatalíticos, viabilizando o desenvolvimento - também no país - da inventividade nesse campo da ciência com geração de dispositivos mais avançados e competitivos frente a tecnologias existentes. Entre os exemplos dessas possibilidades estão as células solares, ${ }^{52,58}$ novos processos oxidativos avançados para tratamento de águas, ${ }^{52}$ purificadores de $\mathrm{ar}^{56} \mathrm{e}$ também diversos dispositivos analíticos com viés ambiental, exemplificados pela digestão de compostos orgânicos para determinação da concentração total de metais em amostras de água ${ }^{59-61}$ e a determinação da Demanda Química de Oxigênio. ${ }^{62}$

\section{AGRADECIMENTOS}

Os autores agradecem ao Conselho Nacional de Desenvolvimento Científico e Tecnológico (CNPq) pela concessão de uma bolsa de doutorado (processo $\mathrm{n}^{\circ}$ 141734-2012-4) e uma de produtividade (processo no $311324 / 2014-2$ ).

\section{REFERÊNCIAS}

1. Hoffmann, M. R.; Martin, S. T.; Choi, W.; Bahnemann, D. W.; Chem. Rev. 1995, 95, 69.

2. Fujishima, A.; Rao, T. N.; Tryk, D. A.; J. Photochem. Photobiol., C $2000,1,1$.
3. Fujishima, A.; Zhang, X.; Tryk, D. A.; Surf. Sci. Rep. 2008, 63, 515.

4. Nogueira R. F. P.; Jardim, W. F.; Quim. Nova 1998, 21, 69.

5. Ziolli, R. L.; Jardim, W. F.; Quim. Nova 1998, 21, 319.

6. Catanho, M.; Malpass, G. R. P.; Motheo, A. J.; Quim. Nova 2006, 29, 983.

7. Cervantes, T. N. M.; Zaia, D. A. M.; Santana, H.; Quim. Nova 2009, 32, 2423.

8. Brunelli, T. F. T.; Guaraldo, T. T.; Paschoal, F. M. M.; Zanoni, M. V. B.; Quim. Nova 2009, 32, 67.

9. Frade, T.; Gomes, A.; Pereira, M. I. S.; Lopes, A.; Ciríaco, L.; Quim. Nova 2012, 35, 30

10. Lark-Horovitz, K.; The present state of physics: The New Electronics; F. S. Brackett: Washington D. C., 1954, pp. 57-157.

11. Shriver, D. F.; Atkins, P.W.; Em Química Inorgânica; Porto Alegre: Bookman, 2003, pp. 128-136.

12. Reif, F.; Fundamentals of Statistical and Thermal Physics; McGrawHill: New York, 1965, p. 341.

13. Madhusudan Reddy, K.; Manorama, S. V.; Ramachandra Reddy, A.; Mater. Chem. Phys. 2002, 78, 239

14. Finklea, H. O.; Semiconductor Electrodes; Elsevier: New York, 1988, pp. 1-18.

15. http://www.doitpoms.ac.uk/tlplib/semiconductors/direct.php, acessada em novembro de 2017

16. Van Zeghbroech Em Principles of Semiconductor Devices; disponível em http://ecee.colorado.edu/ bart/book/, acessada em novembro de 2017.

17. Koole, R.; Groeneveld, E.; Vanmaekelbergh, D.; Meijerink, A.; Donegá, C. M. Em Nanoparticles; Donegá, C. M., ed.; Springer: Verlag-BerlinHeidelberg, 2014; cap. 2.

18. Gaponenko, S. V.; Em Introduction to Nanophotonics, Cambridge University Press: Cambridge, 2010; cap. 4.

19. Henderson, B.; Imbusch, G. F.; Optical Spectroscopy of Inorganic Solids, Clarendon Press: Oxford, 1989; cap. 4 e 5.

20. Groeneveld, E.; Tese de Doutorado, Utrecht University, Holanda, 2012.

21. López, R.; Gómez, R.; J. Sol-Gel Sci. Technol. 2012, 61, 1.

22. Klimov, V. I.; Annu. Rev. Phys. Chem. 2007, 58, 635.

23. Kambhampati, P.; J. Phys. Chem. C 2011, 115, 22089.

24. Rogach, A. L.; Klar, T. A.; Lupton, J. M., Meijerink, A.; Feldmann, J.; J. Mater. Chem. 2009, 19, 1208.

25. Minero, C.; Bahnemann, D.; Robertson, P. Em Environmental Photochemistry Part III; Bahnemann, D., Robertson, P., eds.; Springer: Verlag-Berlin-Heidelberg, 2013, pp. 23-44.

26. Fu, Y.; Cao, W. H.; J. Appl. Phys. 2006, 100, 84324

27. Grätzel, M.; Nature 2001, 414, 338.

28. Bolts, J. M.; Wrighton, M. S.; J. Phys. Chem. 1976, 80, 2641.

29. Gerischer, H.; Physical Chemistry, Academic Press: New York, 1970; Cap. 5.

30. Lewerenz, H. J.; Heller, A.; Di Salvo, F. J.; J. Am. Chem. Soc. 1980, 102, 1877

31. Lewerenz, H. J.; Gerischer, H.; Lubke, M.; J. Electrochem. Soc. 1984, 131,100 .

32. Canfield, D.; Furtak, T.; Parkinson, B. A.; J. Appl. Phys. 1980, 51, 6018.

33. Shockley, W.; Queisser, H. J.; J. Appl. Phys. 1961, 32, 510.

34. Razzini, G.; Bicelli, L. P.; Pini, G.; Scrosati, B.; J. Electrochem. Soc. 1981, 128, 2134.

35. Bicelli, L. P.; Razzini, G., Surf. Technol. 1983, 20, 383.

36. White, H. S.; Abruna, H. D.; Bard, A. J.; J. Electrochem. Soc. 1982, 129 , 265.

37. Fornarini, L.; Stirpe, F.; Scrosati, B.; J. Electrochem. Soc. 1983, 130, 2184

38. Hagfeldt, A.; Grätzel, M.; Chem. Rev. 1995, 95, 49.

39. Alivisatos, P.; Pure Appl. Chem. 2000, 72, 3.

40. Rabouw, F. T.; Donega, C. M.; Top. Curr. Chem. 2016, 374, 58. 
41. Cahen, D.; Grätzel, M.; Guillemoles, J. F.; Hodes, G. Em Electrochemistry of Nanomaterials; Hodes, G., ed.; Wiley: VCH Verlag, 2001, p. 201.

42. Hodes, G.; Howell, I. D. J.; Peter, L. M.; J. Electrochem. Soc. 1992, 139, 3136.

43. Jiang, D.; Zhao, H.; Zhang, S.; John, R.; J. Phys. Chem. B 2003, 107, 12774.

44. Hodes, G.; Albu-Yaron, A.; Decker, F.; Motisuke, P.; Phys. Rev. B 1987, 36, 4215.

45. Brus, L., Phys. Rev. B 1996, 53, 4649.

46. Villanueva-Cab, J.; Jang, S-R.; Halverson, A. F.; Zhu, K.; Frank, A. J.; Nano Lett. 2014, 14, 2305.

47. Baccaro, A. L. B.; Gutz, I. G. R.; Electrochim. Acta 2016, 214, 295.

48. Berger, T.; Lana-Villarreal, T.; Monllor-Satoca, D.; Gómez, R.; Electrochem. Commun. 2006, 8, 1713.

49. Jiang, D.; Zhao, H.; Zhang, S.; John, R.; J. Catal. 2004, 223, 212.

50. Regazzoni, A. E.; Mandelbaum, P.; Matsuyoshi, M.; Schiller, S.; Bilmes, S. A.; Blesa, M. A.; Langmuir 1998, 14, 868.

51. Jiang, D.; Zhao, H.; Zhang, S.; John, R.; J. Photochem. Photobiol. A 2006, 177, 253
52. Bessegato, G. G.; Guaraldo, T. T.; Brito, J. F.; Brugnera, M.F.; Zanoni, M. V. B.; Electrocatalysis 2015, 6, 415.

53. Daghrir, R.; Drogui, P.; Robert, D.; J. Photochem. Photobiol. A 2012, $238,41$.

54. Zhang, Y.; Xiong, X.; Han, Y.; Zhang, X.; Shen, F.; Deng, S.; Xiao, H.; Yang, X.; Yang, G.; Peng, H.; Chemosphere 2012, 88, 145.

55. Egerton, T. A.; J. Chem. Technol. Biotechnol. 2011, 86, 1024.

56. Zhang, H; Chen, G.; Bahnemann, D. W.; J. Mater. Chem. 2009, 19, 5089 .

57. Karanasios, N.; Georgieva, J.; Valova, E.; Armyanov, S.; Litsardakis, G.; Sotiropoulos, S.; Curr. Org. Chem. 2015, 19, 512.

58. Lianos, P.; Appl. Catal., B 2017, 210, 235.

59. Cavicchioli, A.; Gutz, I. G. R.; Anal. Chim. Acta 2001, 445, 127.

60. Daniel, D.; Gutz, I. G. R.; Electrochem. Commun. 2007, 9, 522.

61. Baccaro, A. L. B.; Gutz, I. G. R.; Electrochem. Commun. 2013, 31, 28.

62. Zhao, H.; Jiang, D.; Zhang, S.; Catterall, K.; John, R.; Anal Chem. 2004, $76,155$. 